$$
\begin{aligned}
& \text { 震 } \\
& \overline{\overline{\underline{\underline{1 .||}}}}
\end{aligned}
$$

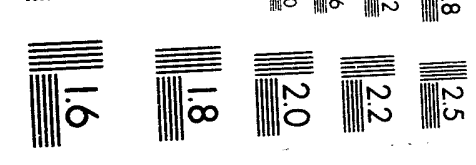



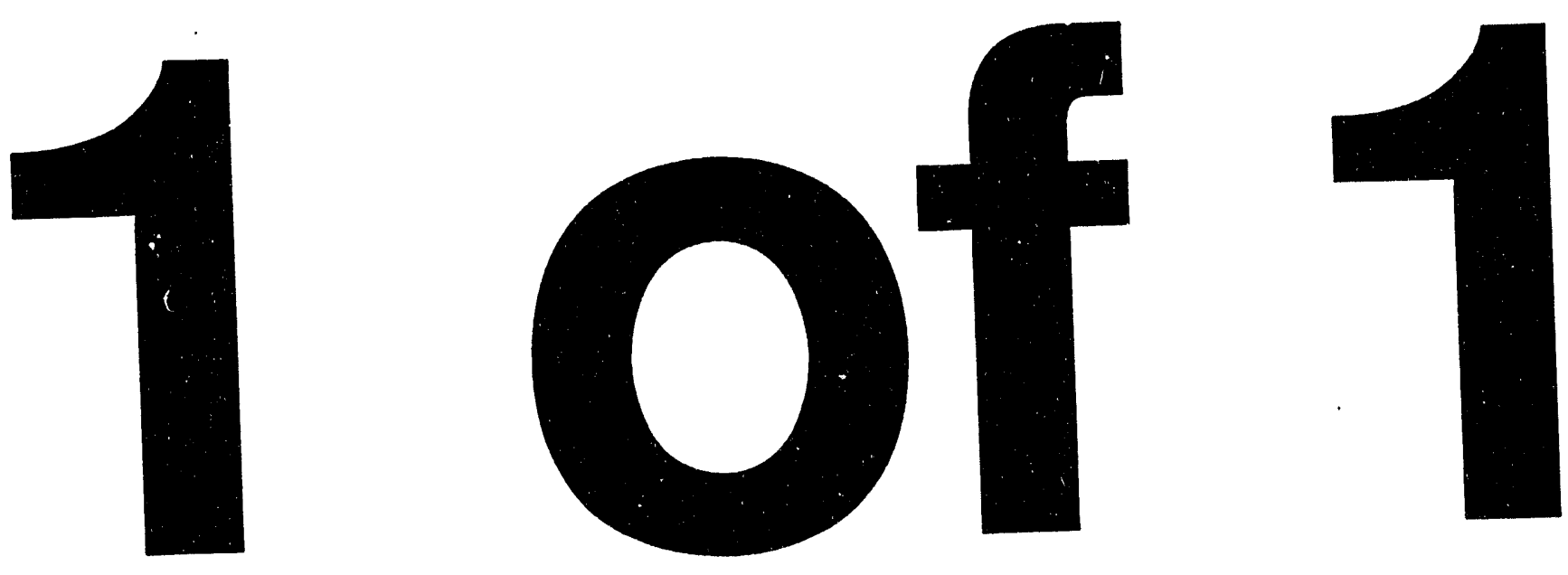
UCRL-ID-116819

\title{
Program EPICSHOW: A Computer Code to Allow Interactive Viewing of the EPIC Data Libraries (Version 94-1)
}

\author{
Dermott E. Cullen \\ University of California \\ Lawrence Livermore National Laboratory \\ L-294, P.O. Box 808 \\ Livermore, CA 94550
}

February 1994

This is an informal report intended primarily for internal or limited external distribution. The opinions and conclusions stated are those of the author and may or may not be those of the Laboratory.

Work performed under the auspices of the U.S. Department of Energy by the Lawrence Livermore National Laboratory under Contract W-7405-Eng-48. 


\section{DISCLAIMER}

This document was prepared as an account of work sponsored by an agency of the United States Government. Neither the United States Government nor the University of California nor any of their employees, makes any warranty, express or implied, or assumes any legal liability or responsibility for the accuracy, completeness, or usefulness of any information, apparatus, product, or process disclosed, or represents that its use would not infringe privately owned rights. Reference herein to any specific commercial products, process, or service by trade name, trademark, manufacturer, or otherwise, does not necessarily constitute or imply its endorsement, recommendation, or favoring by the United States Government or the University of California. The views and opinions of authors expressed herein do not necessarily state or reflect those of the United States Government or the University of California, and shall not be used for advertising or product endorsement purposes.

This report has been reproduced directly from the best available copy.

Available to DOE and DOE contractors from the Office of Scientific and Technical Information

P.O. Box 62, Oak Ridge, TN 37831

Prices available from (615) 576-8401, FTS 626-8401

Available to the public from the

National Technical Information Service

U.S. Department of Commerce

5285 port Koyal Rd.,

Springlicld, VA 2216 
Program EPICSHOW: A Computer Code to Allow Interactive Viewing of the EPIC

Data Libraries

(Version 94-1)

by

Dermott E. Cullen

Lawrence Livermore National Laboratory

L-294, P.O. Box 808

livermore, Ca 94550

February 1994 
Program EPICSHOW: A Computer Code to Allow Interactive Viewing of the EPIC

Data Libraries

(Version 94-1)

$$
\text { by }
$$

Dermott E. Cullen

Lawrence Livermore National Laboratory

L-294, P.O. Box 808

Livermore, Ca 94550

February 1994

Table of Contents

1) The EPIC System Overview.....................................3

2) The Epicshow code....................................................4

3) Contents of the Data Bases.......................................4

4) Implementing Epicshow............................................6

5) What is Epicshow?...............................................6

6) Brief Introduction to the Menu Options...............6

7) A Guided tour of Epicshow.....................................10

8) Z+10, Z-10, etc.: Selecting a Target.......................12

9) Freeze!!!................................................................13

10) Major, Minor, etc.: Selecting a Type of Data....14

11) Photon, Electron, etc.: Selecting a Projectile.....14

12) Example Target and Projectile Output.................14

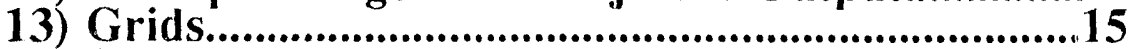

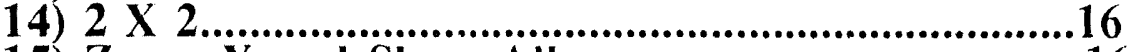

15) Zoom $X$ and Show All.............................................16

16) Points.....................................................................16

17) Ratio...................................................................17

18) $\operatorname{Lin} / \log X$ and $Y$ : Linear or Log Scaling............18

19) barn-1/cm: Microscopic or Macroscopic...............18

20) Listing: Tabulated Output Listings........................19

21) Pstscript: Postscript Output.....................................20

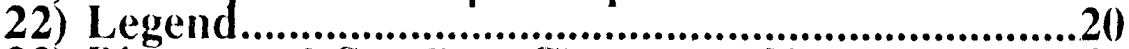

23) Bigger and Smaller: Character Size......................21

24) Bottoms Up and No Bottom................................21

25) Interpolation of Data..............................................22

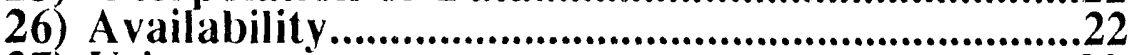

27) Using your mouse.....................................................22

28) Size of Data Bases................................................23

29) Epicshow's Standard Graphic Interface..............24

30) Postscript Output to Local Printer.......................25

31) Acknowledgements.................................................26 


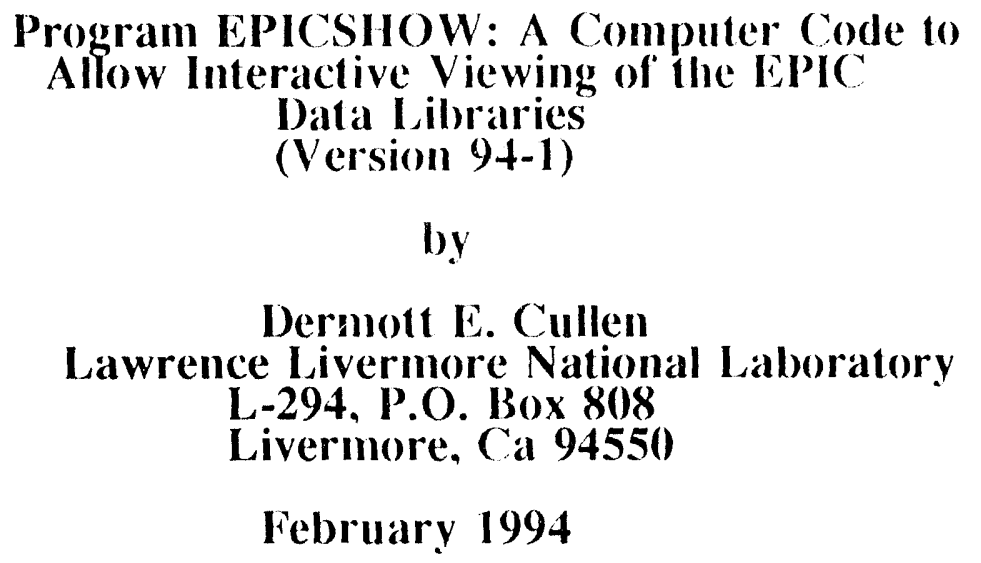

1) The EPIC System Overview

The EPIC (Electron Photon Interaction Code) system includes not only data for electrons and photons, but also data for positrons, light charged particles (proton, deuteron, triton, helium-3 and alpha) and neutrons. All of these data libraries are maintained in a simple, standard tabular character based format, so they can be easily moved to any computer. Once they have been moved to any computer they are converted to binary, random access files, using standard FORTRAN, so that they can be quickly and efficiently accessed on that computer. 


\section{2) The Epicshow code}

Epicshow is the part of the EPIC system that allows viewers to access and interact with the EPIC data bases. This code can be used for a variety of purposes. At the most basic level this code is an interactive replacement for our UCRL-50400 series publications on photon, electron and neutron data. The EPIC libraries contain all of the data presented in these publications, and by using Epicshow you can not only view the data as presented in these publications, you can also interact with the data, e.g., zoom in to examine any energy range in more detail, compare data for different target materials or projectiles side by side. At a more sophisticated level it can be used to compare the data libraries and the results of EPIC transport calculations, in order to better understand the effects observed in the results of calculations.

\section{3) Contents of the Data Bases}

Each data base is for a given type of projectile: photons, electrons, positrons, charged particles and neutrons. Each data base contains data for a variety of targets, either elemental or isotopic.

The EPIC data bases include data for elements hydrogen $(Z=1)$ through fermium $(Z=100)$ over the energy range $10 \mathrm{eV}$ to $1 \mathrm{Gev}$ for photons, electrons, positrons and light charged particles (protons, deuterons, tritons, helium-3 and alpha particles). EPIC uses analytical expressions to extend this data to higher energies. The EPIC neutron data base includes data for elements and isotopes over the energy range 
1.0e-(04 eV to $20 \mathrm{MeV}$, with provisions to incorporate higher energy data as it becomes available. See the EPIC report for a description of the sources of this data.

In this report I refer to types of data as major, minor, deposition, range and straggling. Major and minor refer to photon, electron, positron and neutron cross sections; no cross sections are included for charged particles. For photons major cross sections include total, photoelectric, coherent, incoherent, pair and triplet cross sections. For electrons major cross sections include total, ionization, bremsstrahlung, excitation, elastic and elastic transport cross sections. For photons and electrons minor cross sections are the photoelectric and ionization subshell cross sections, respectively. For neutrons major cross sections include total, elastic, capture, fission and total inelastic cross sections. Minor cross sections include inelastic level, $(n, 2 n)$, etc.

Energy deposition data is included for all projectiles in the form of $\mathrm{MeV}$ lost per collision (microscopic data) and $\mathrm{MeV} / \mathrm{cm}$ (macroscopic data).

Range and straggling data is included for electrons, positrons and charged particles. No range or straggling data is included for photons and neutrons. 


\section{4) Implementing Epicshow}

As in the case of EPIC, Epicshow is designed to run on virtually any computer. As distributed the code includes standard graphics interfaces for IBM-PCs and SUN workstations. This standard interface is so simple that it can be easily adapted to run on any computer. For details, see the section on the standard graphics interface.

5) What is Epicshow?

Epicshow is a mouse driven, interactive system; no keyboard or any input other than from a mouse is required by the user. The computer screen is divided into two parts: 1) the upper portion of the screen is used to display messages to users (watch the upper, right hand corner) and a menu of thirty options, 2) the lower portion of the screen is used to display the EPIC data.

The code starts by identifying itself on the first frame; press your mouse or any keyboard key to start. The next frame will be the hydrogen photon interaction data. From this point on the user is free to select any of the menu options.

6) Brief Introduction to the Menu Options

The remainder of this report explains all of the currently available menu options and illustrates the results obtained. The reader should be aware that by the time this report is published these options will have changed. Not to worry! When you receive the code read the file README for the most up-to-date description of all of the then current options. 
First let's quickly review the available options; then we will see what results you obtain when you select one of them. The following is merely a list of all options and a brief description of each as contained in the file PAGE.DAT that you receive with Epicshow. This files assigns a keyword to each of the menu boxes at the box of your screen. If you do not like the keyword currently used to describe any option, please feel free to change the keyword to anything that you would like to describe the same option.

The currently available options are,

$1 \operatorname{Lin} / \log X=$ switch between linear and $\log x$ scaling

$2 \operatorname{Lin} / \log Y=$ switch between linear and $\log y$ scaling

3 Points = switch between showing and not showing data points on each curve

5 Freeze!!! = freeze the display - select as many options as you like and then select Freeze!!! again to continue WARNING - this cannot be used to queue a number of plots - it can only be used to change options for the next plot you request after you select Freeze!!! the second time select Same $\mathrm{Z}$ to see the data you selected with all of the options you selected

6 Zoom $X=$ use the mouse to select the lower and upper $x$ limits of the next plot (to see data in more detail)

7 Show All $=$ undo zoom - show the entire $x$ range

8 Ratio $=$ show the ratio of all curves to the first curve 
9 No Bottom = freeze the position of the bottom of the screen (prevent BottomsUp from working)

10 BottomsUp = move the bottom of the screen up $1 / 2$ " (some displays use the bottom of each window for identification, which overlays the axis labels - this option can be used to insure you can see the axis label)

11 Grid $+1=$ change to grid +1 (there are 6 difference grids)

12 Grid $-1=$ change to grid -1 (rather than my explaining them, you just try them)

15 barn-1/cm = switch between microscopic (barns) and macroscopic $(1 / \mathrm{cm})$ cross sections

16 Legend = switch between displaying and not displaying the legend box identifying each curve

17 Bigger = make the characters bigger

18 Smaller = make the characters smaller

21 Photons = select photon data for next plot (same $\mathrm{Z}$ and type)

22 Electrons = select electron data for next plot (same $\mathrm{Z}$ and type)

23 Positrons = select positron data for next plot (same $\mathrm{Z}$ and type)

24 Charged = select charged particles for next plot (same $\mathrm{Z}$ and type)

25 Neutrons = select neutron data for next plot (same $\mathrm{Z}$ and type)

26 Major = select major cross sections for next plot

27 Minor = select minor cross sections for next plot

28 Deposit = select energy deposit for next plot

29 Range = select range for next plot 
30 Straggle = select straggling for next plot

(the above 5 are what $I$ refer 10 as data types)

$31 \mathrm{Z}+1$ = display data for the next $\mathrm{Z}$

$32 \mathrm{Z}+10=$ display data for $\mathrm{Z}+10$

$33 \mathrm{Z}-1=$ display data for $\mathrm{Z}-1$

$34 \mathrm{Z}-10 \quad=$ display data for $\mathrm{Z}-10$

35 Same $\mathrm{Z}=$ display data for same $\mathrm{Z}$ - repeat last plot usually used to obtain Postscript output (the above 5 options can be used to quickly position yourself anywhere in the periodic table without having to type anything, e.g., what $Z$ ?)

$362 \times 2=$ switch between 1 full sized plot and $+(2 \times 2)$ plots on the display (this option is very useful to allow you to compare different types of the data on the screen, side by side)

37 Listing = list data for the currently displayed data (current Z, all of electron or photon, etc. data)

38 Pstscript = switch between Postscript output ON and OFF 40 Stop = WHAT CAN I SAY!!! 
7) A Guided tour of Epicshow

That's very nice! But what the heck do these options do?

If you already have the code sit down at your computer terminal now and I'll take you on a trial run using Epicshow; if you don't have the code now, you can use your imagination.

When the code is started it first identifies itself by displaying the following figure; this rells you what version of the code you are using and gives you your first view of the menu. Press any button on your mouse or any keyboard key to continue. 


\begin{tabular}{|l|l|l|l|l|l|l|l|l|}
\hline EPICV IEW & Version 94-1) \\
\hline Lin/Log X & Zoom X & Grid +1 & Legend & Photons & Ma jor & $Z+1$ & 2 X 2 \\
\hline Lin/Log Y & Show All & Grid -1 & Bigger & Electrons & Minor & $Z+10$ & Listing \\
\hline Points & Ratio & & Smaller & Positrons & Deposit & $Z-1$ & Pstscript \\
\hline & No Bottom & & & Charged & Range & Z -10 & \\
\hline Freeze!!! & BottomsUp & barn-1/cm & & Neutrons & Straggle & Same Z & Stop \\
\hline
\end{tabular}

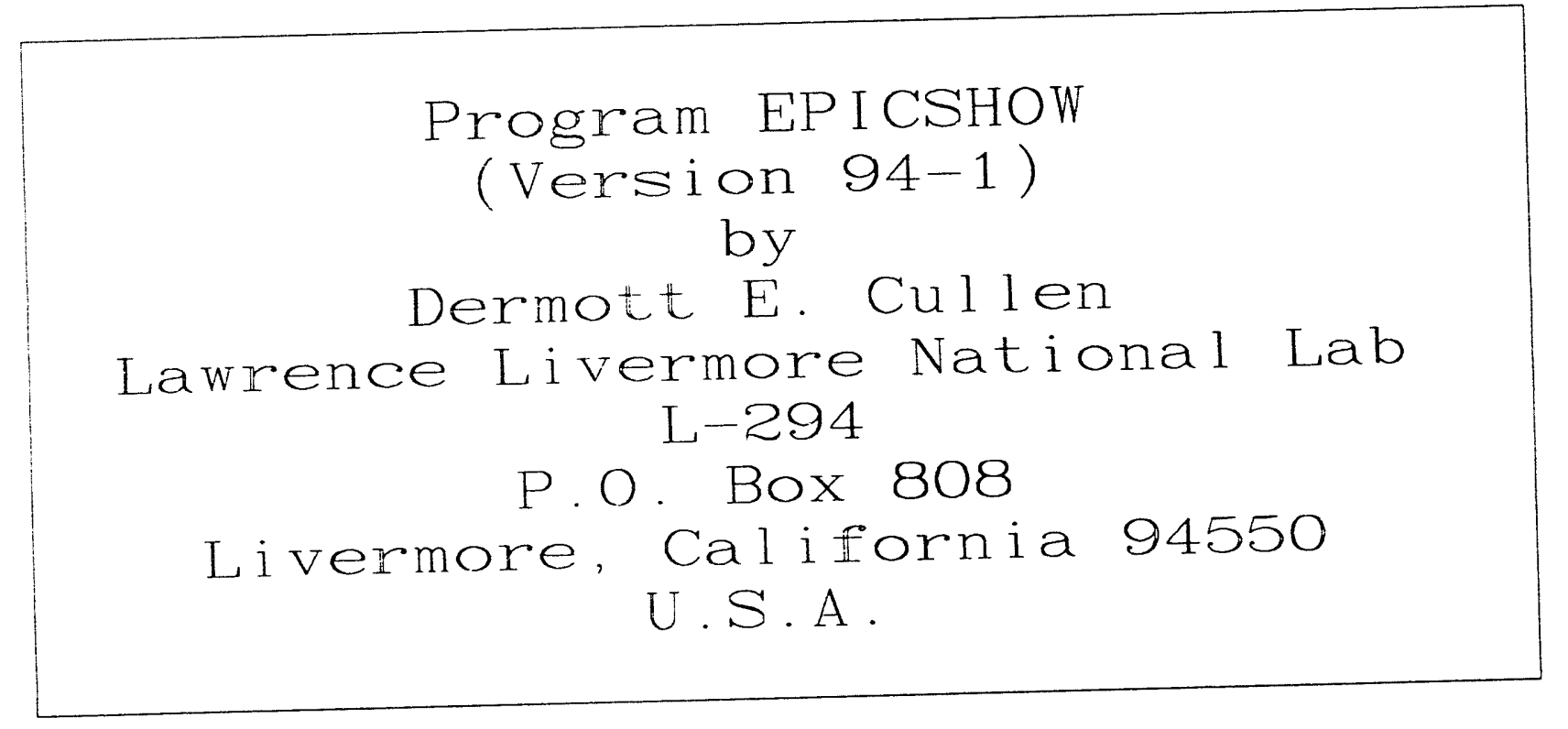


The first actual plot will be of the hydrogen major photon cross sections, as shown on the following figure. 


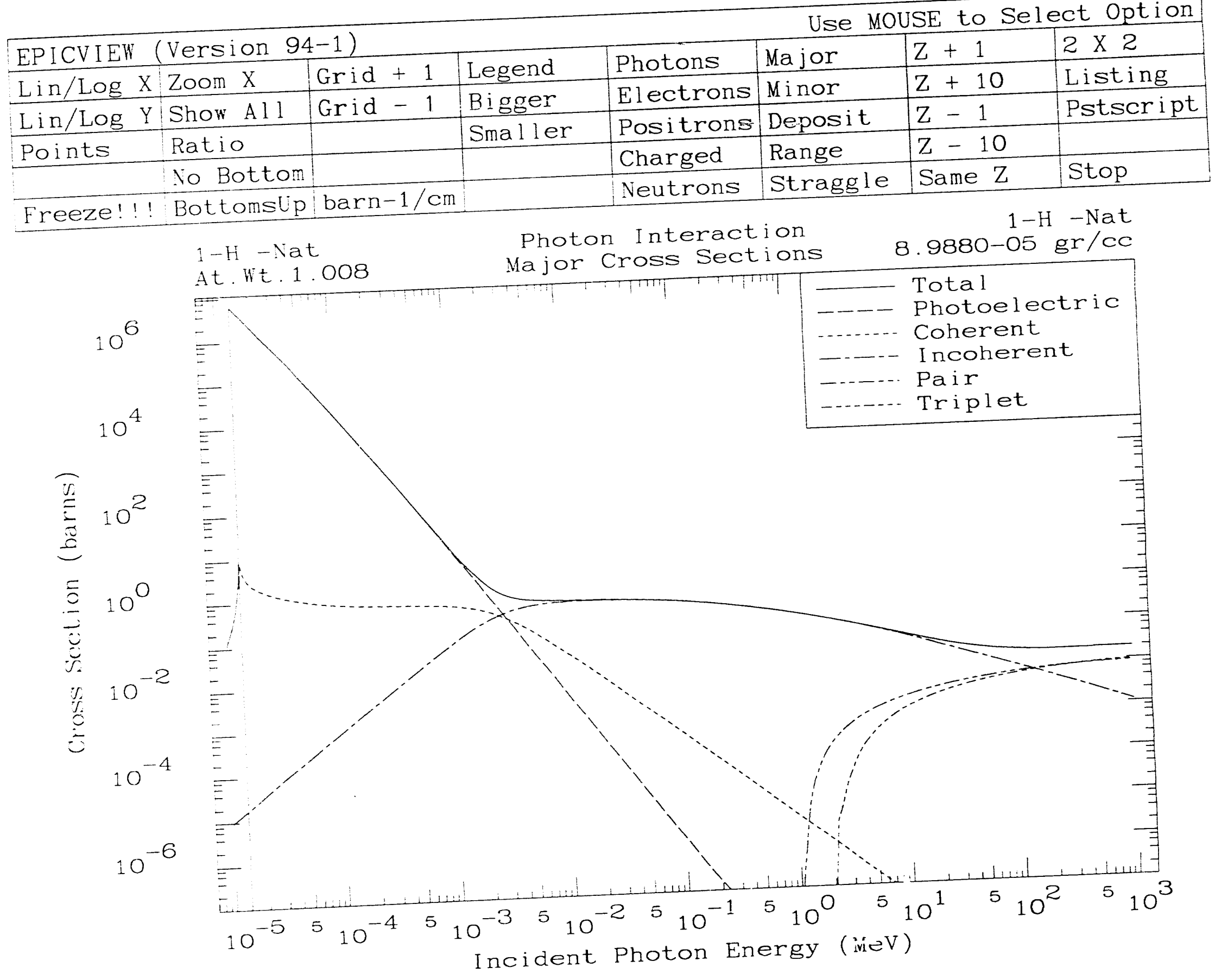


8) Z+10, Z-10, etc.: Selecting a Target

You can use the $\mathrm{Z}+10, \mathrm{Z}-10, \mathrm{Z}+1, \mathrm{Z}-1$ and the Same $\mathrm{Z}$ options to quickly position yourself to anyplace in the periodic table. If you wish to see the data between where you are now positioned and where you would like to be just select a combination of these options to position yourself. A much quicker method is to use the Freeze!!! option. Let's see just how quickly we can do this. Assume we are interested in uranium data. Select the Freeze!!! option to lock the screen and then select $\mathrm{Z}+10$ nine times and $\mathrm{Z}+1$ once and you are there. Select Freeze!!! again, to unclock the screen and Same $\mathrm{Z}$ to display the current data - you are now looking at the uranium major photon interaction cross sections, as shown in the following figure. This whole process is so fast it takes Ionger to explain it here than it takes to accomplish this using the code essentially as fast as you can press your mouse button a few times you can position yourself anywhere in the periodic table. 


\section{9) Freeze!!!}

When you select an option from the menu, in most cases the result will be the next plot. Usually this is adequate to display any data. However, if you want to display different types of data on the same screen in particular positions relative to one another, so that you can compare them, you may need to select more than one option before the next plot. The Freeze!!! option gives you this ability.

When the display is locked by the Freeze!!! option, you can select any combination of options from the menu before the next plot. Just so you don't get lost someplace in the periodic table because you don't remember how many times you selected the $Z+10$ option, note, on the screen, on the top line in the upper, left hand corner after the program identification the current $\mathrm{Z}$ is always displayed, so that you know where you are.

When you have finished selecting all of your options, select the Freeze!!! option again, to unlock the display - now any option that you select will produce the next plot. In the above example we used the Freeze!!! to quickly position ourselves in the periodic table without any delay due to plotting any data between hydrogen and uranium. Below we will see examples of using the Freeze!!! command to compose plots to compare data.

WARNING - Freege!! cannot be used to queue a number of plots to be displayed; it can only be used to change options for the next plot that you request. 
10) Major, Minor, etc.: Selecting a Type of Data

The options Major, Minor, Deposit, Range and Straggle can be used to display different types of data. The options Major and Minor refer to Photon, Electron, Positron and Neutron Major and Minor cross sections. These options have no meaning and will be ignored for charged particles. The option Deposit applies to all projectiles and defines the expected average energy loss by the projectile in $\mathrm{MeV} / \mathrm{cm}$. The options Range and Straggle are used here only to apply to charged particles (electron and positron ranges will appear in the tabulated output, but not in graphic form).

11) Photon, Electron, etc.: Selecting a Projectile The options Photons, Electrons, Positrons, Charged (charged particles) and Neutrons can be used to select the projectile of interest. The charged particles include protons, deuterons, tritons, helium-3 and alpha particles.

12) Example Target and Projectile Output The following pages illustrate the results displayed when after pusitioning to the uranium photon major cross sections (first figure) I selected the options Minor (next figure), Deposit (next), Electron (note, still Deposit), Major and Minor. Starting from the initial figure the following five figures were produces using only five clicks of the mouse: what could be easier? 


\begin{tabular}{|c|c|c|c|c|c|c|c|}
\hline \multicolumn{5}{|c|}{ EPICVIEW (Version 94-1) } & \multicolumn{3}{|c|}{ Use MOUSE to Select Option } \\
\hline $\operatorname{Lin} / \log x$ & Zoom X & Grid +1 & Legend & Photons & Ma jor & $\mathrm{Z}+1$ & $2 \times 2$ \\
\hline $\operatorname{Lin} / \log Y$ & Show All & Grid -1 & Bigger & Electrons & Minor & $Z+10$ & Listing \\
\hline \multirow[t]{2}{*}{ Points } & Ratio & & Smaller & Positrons & Deposit & $Z-1$ & Pstscript \\
\hline & No Bottom & & & Charged & Range & $Z-10$ & \\
\hline Freeze!!! & Bot tomsup & barn-1/cm & & Neutrons & Straggle & Same Z & Stop \\
\hline
\end{tabular}

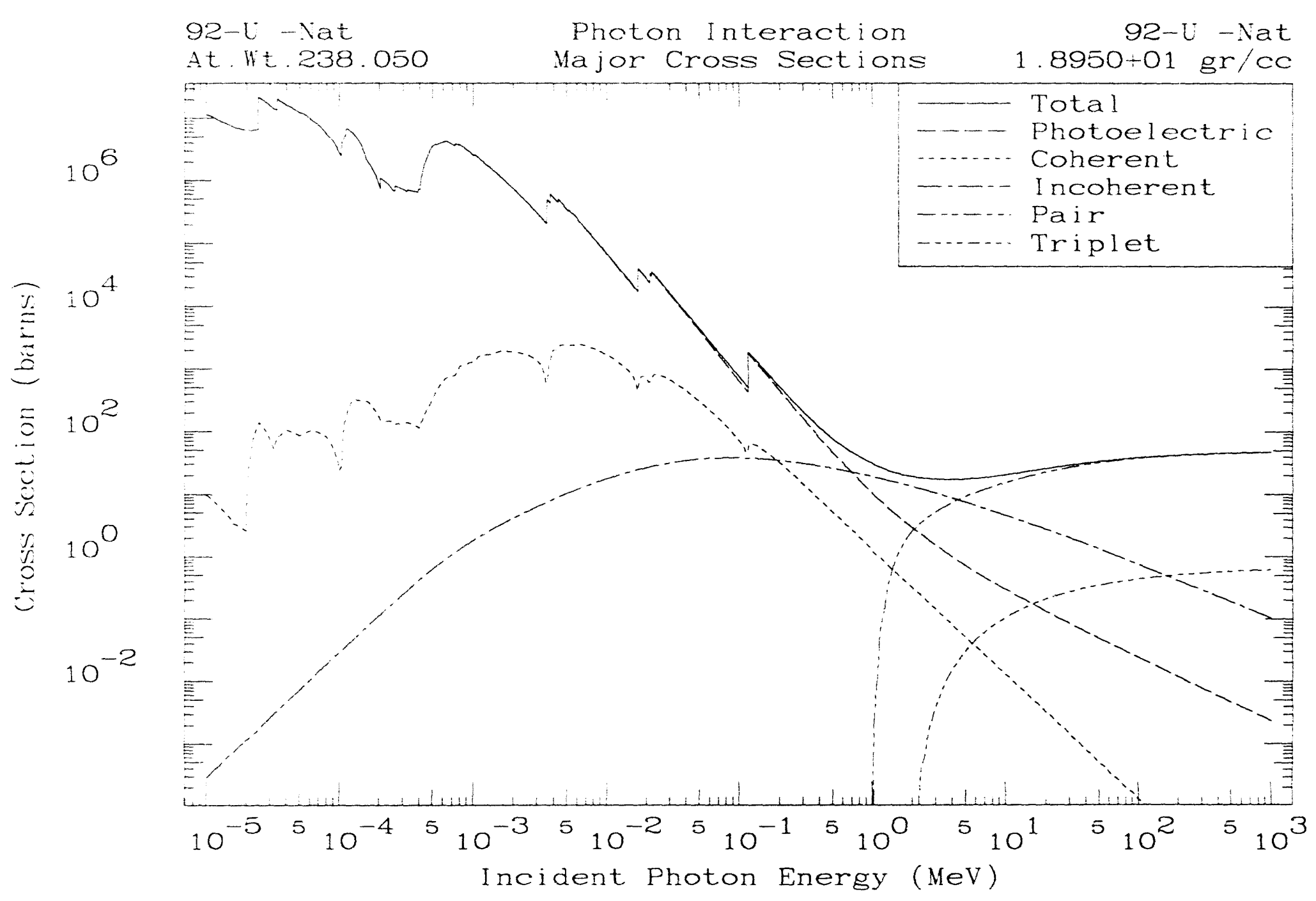




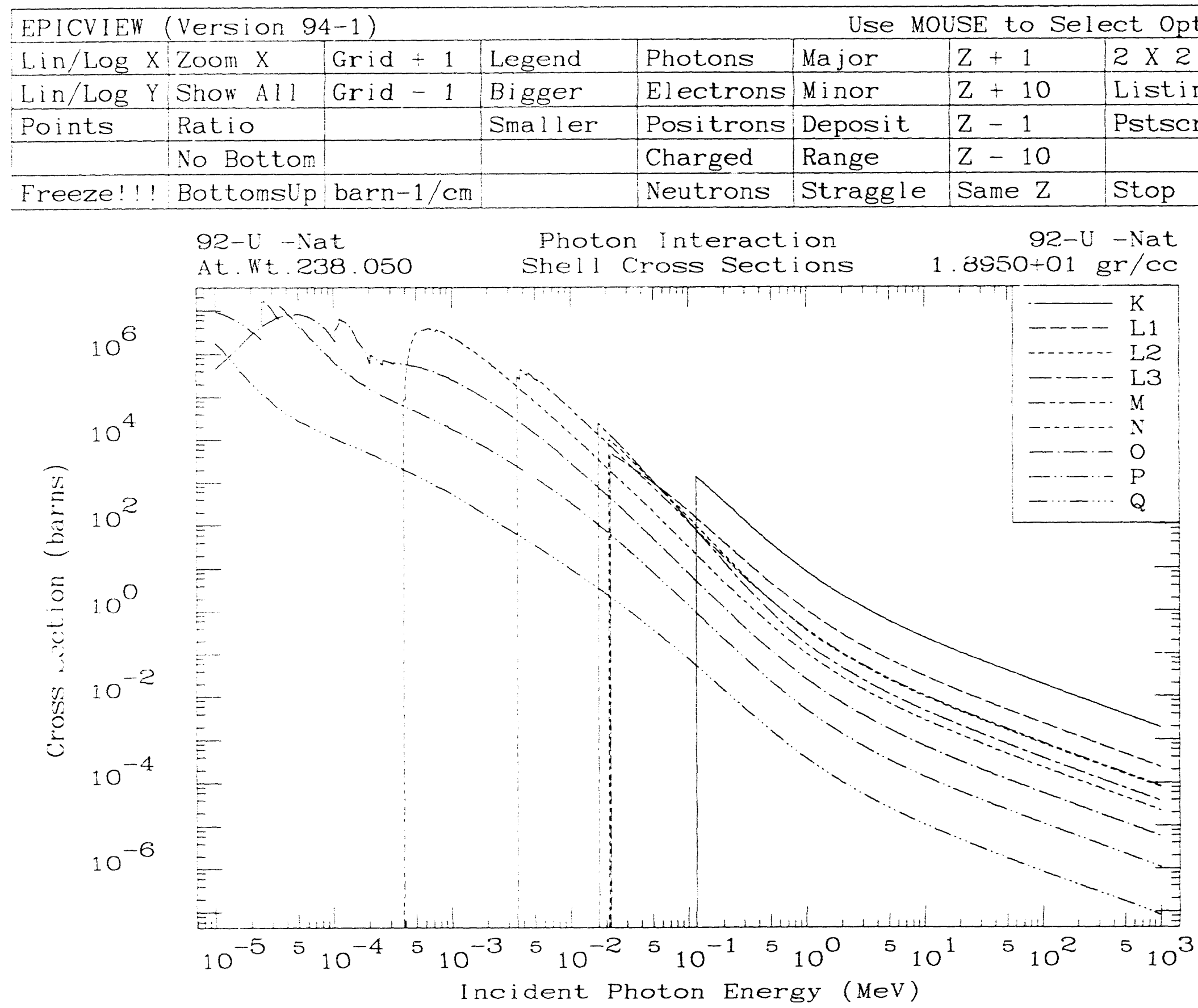




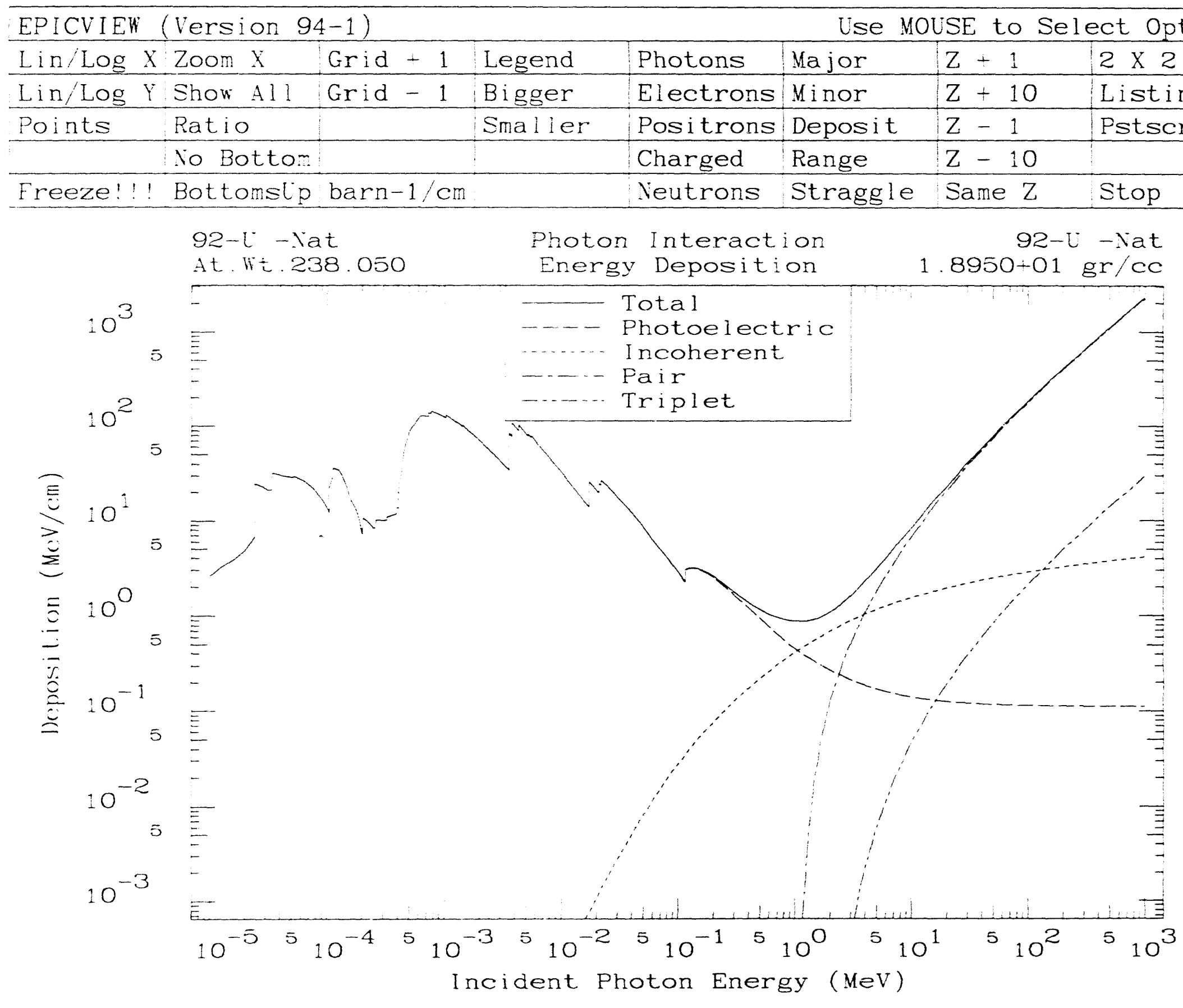




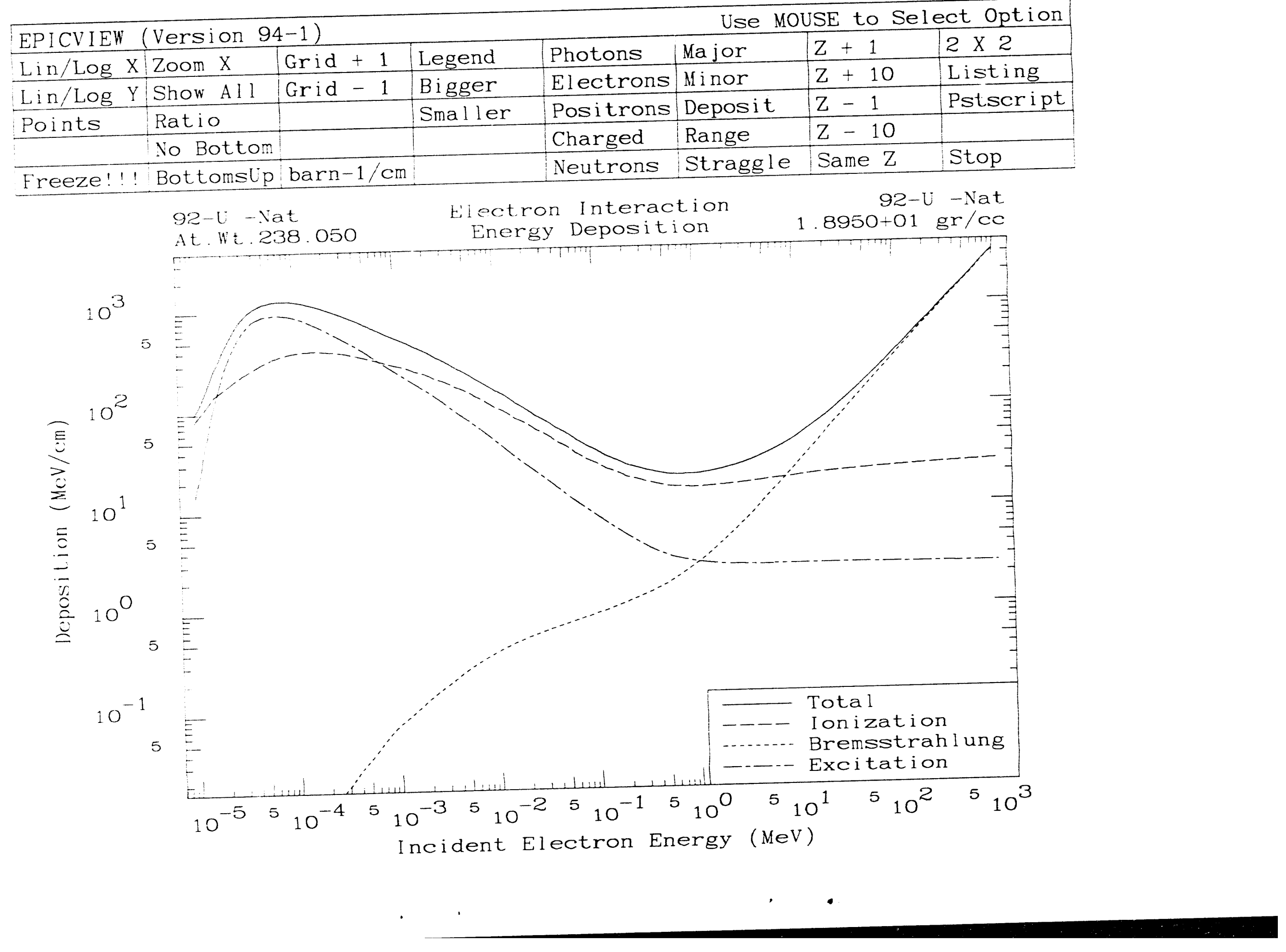




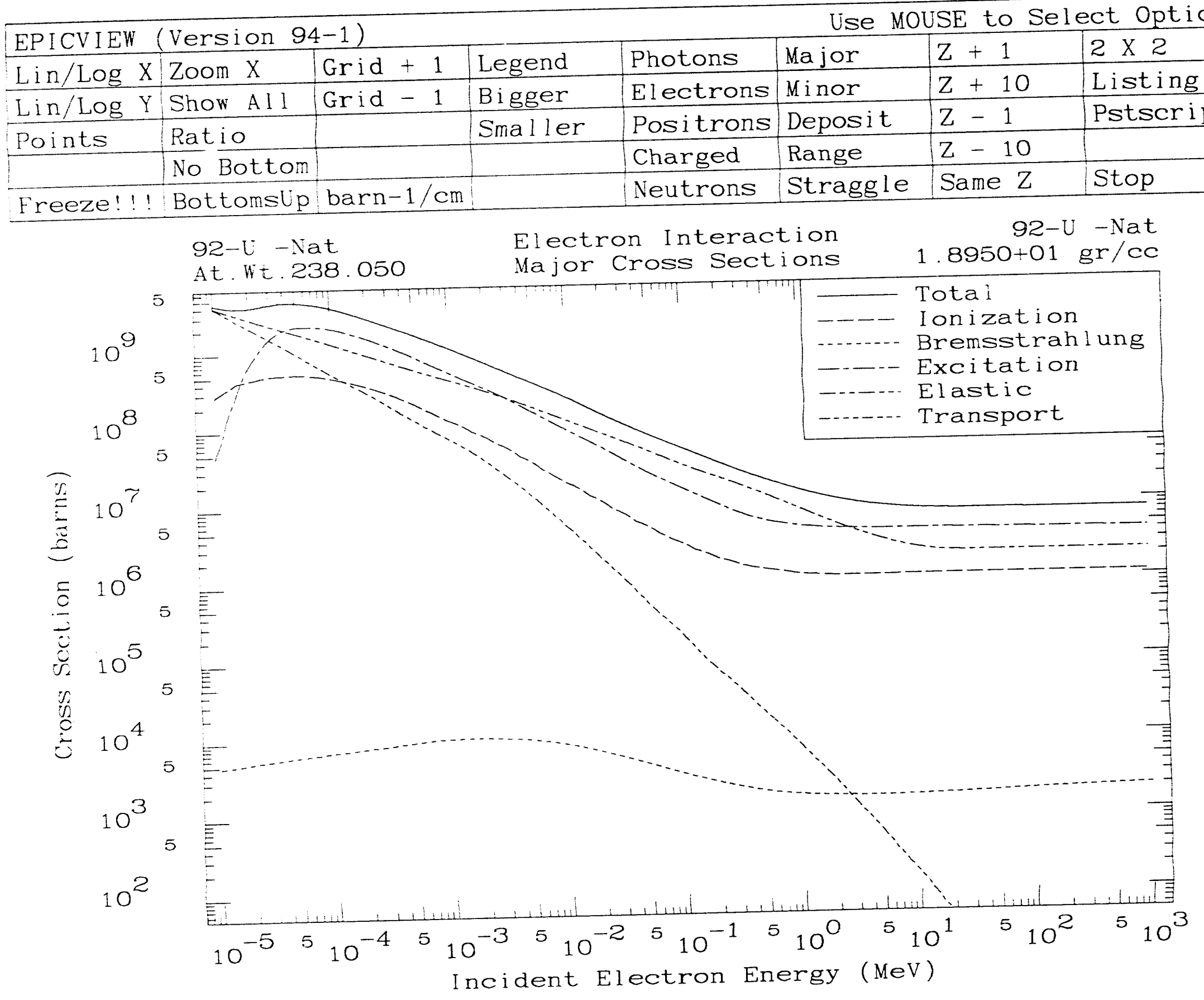




\begin{tabular}{|l|l|l|l|l|l|l|l|}
\hline EPICVIEW & Use MOUSE to Select Option \\
\hline Lin/Log X & Zoom X & Grid +1 & Legend & Photons & Ma jor & $Z+1$ & $2 X$ Z \\
\hline Lin/Log Y & Show All & Grid -1 & Bigger & Electrons & Minor & $Z+10$ & Listing \\
\hline Points & Ratio & & Smaller & Positrons & Deposit & $Z-1$ & Pstscript \\
\hline & No Bottom & & & Charged & Range & Z -10 & 10 \\
\hline Freeze!!! & BottomsUp & barn-1/cm & & Neutrons & Straggle & Same Z & Stop \\
\hline
\end{tabular}

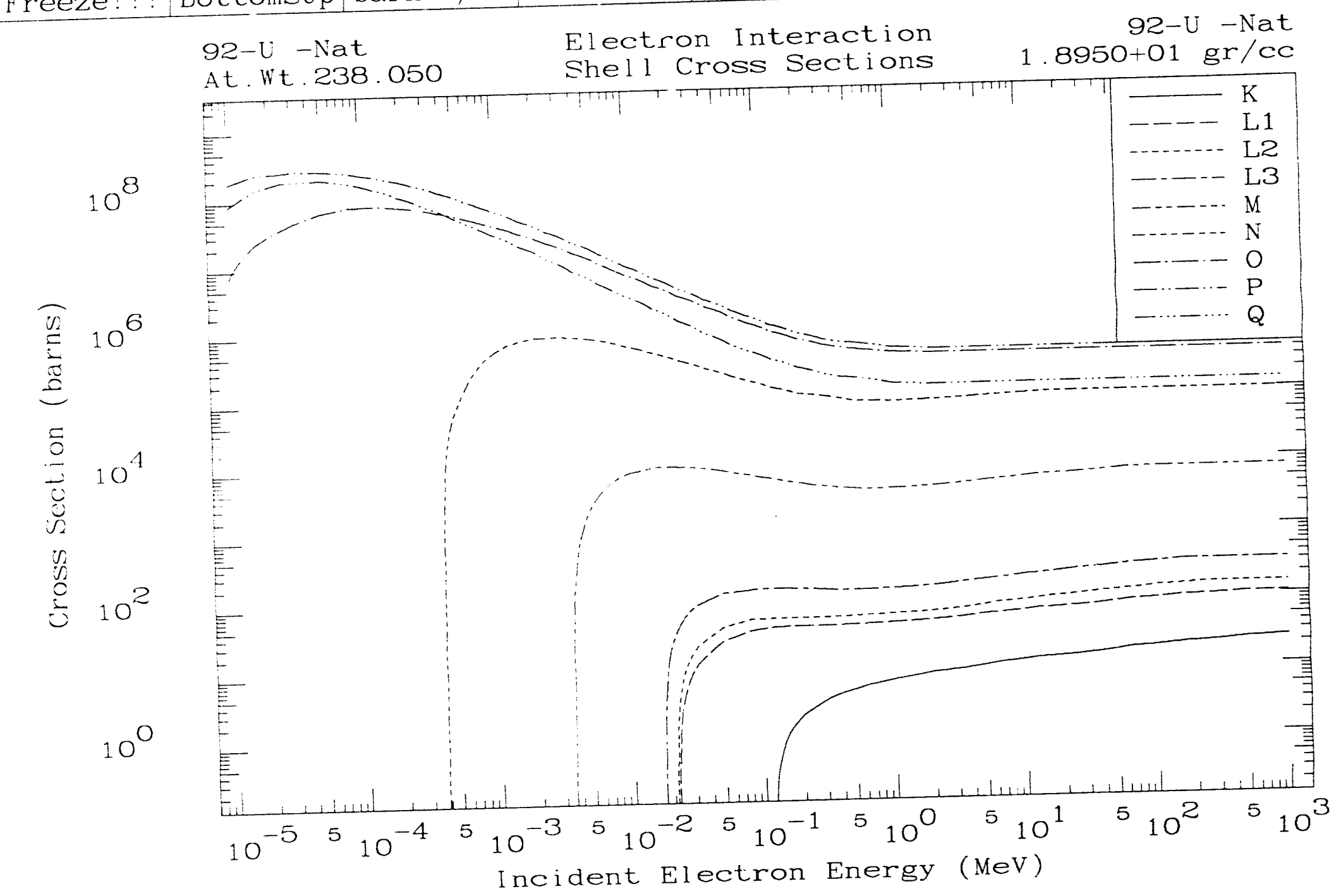




\section{3) Grids}

If you are interested only in the general shape of the data the previous figures are adequate. But if you want to try and actually determine the magnitude of the data you need a grid. Epicshow includes six different types of grids, starting from the previously shown tick marks on the border and progressively including more and more detail. These grids are controlled by the menu options Grid + 1 (more detail) and Grid - 1 (less detail). The program starts with only tick marks on the border (as shown on previous figures). The following five figures illustrate remaining five grid types in all cases using exactly the same iron major photon cross sections. 


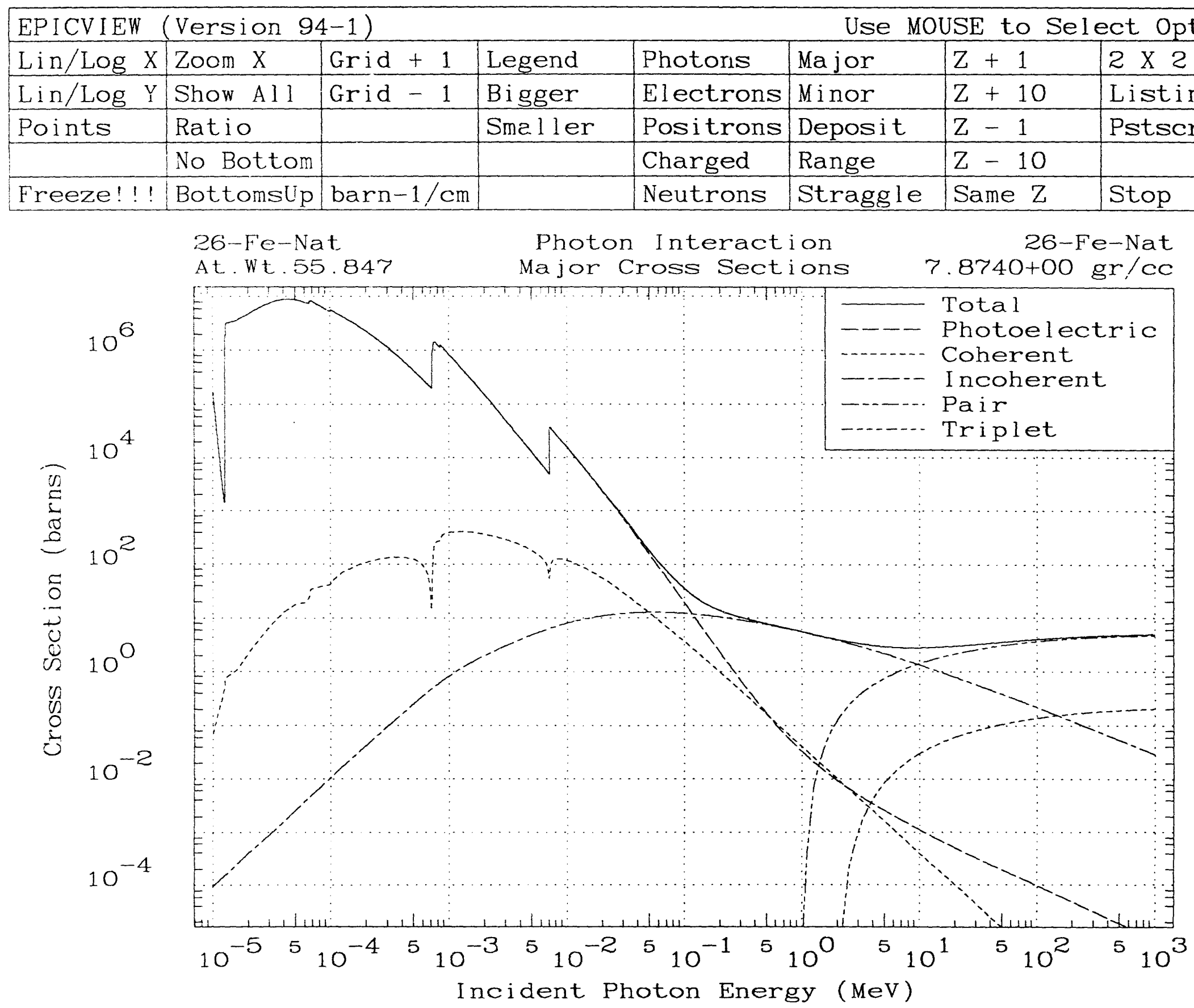




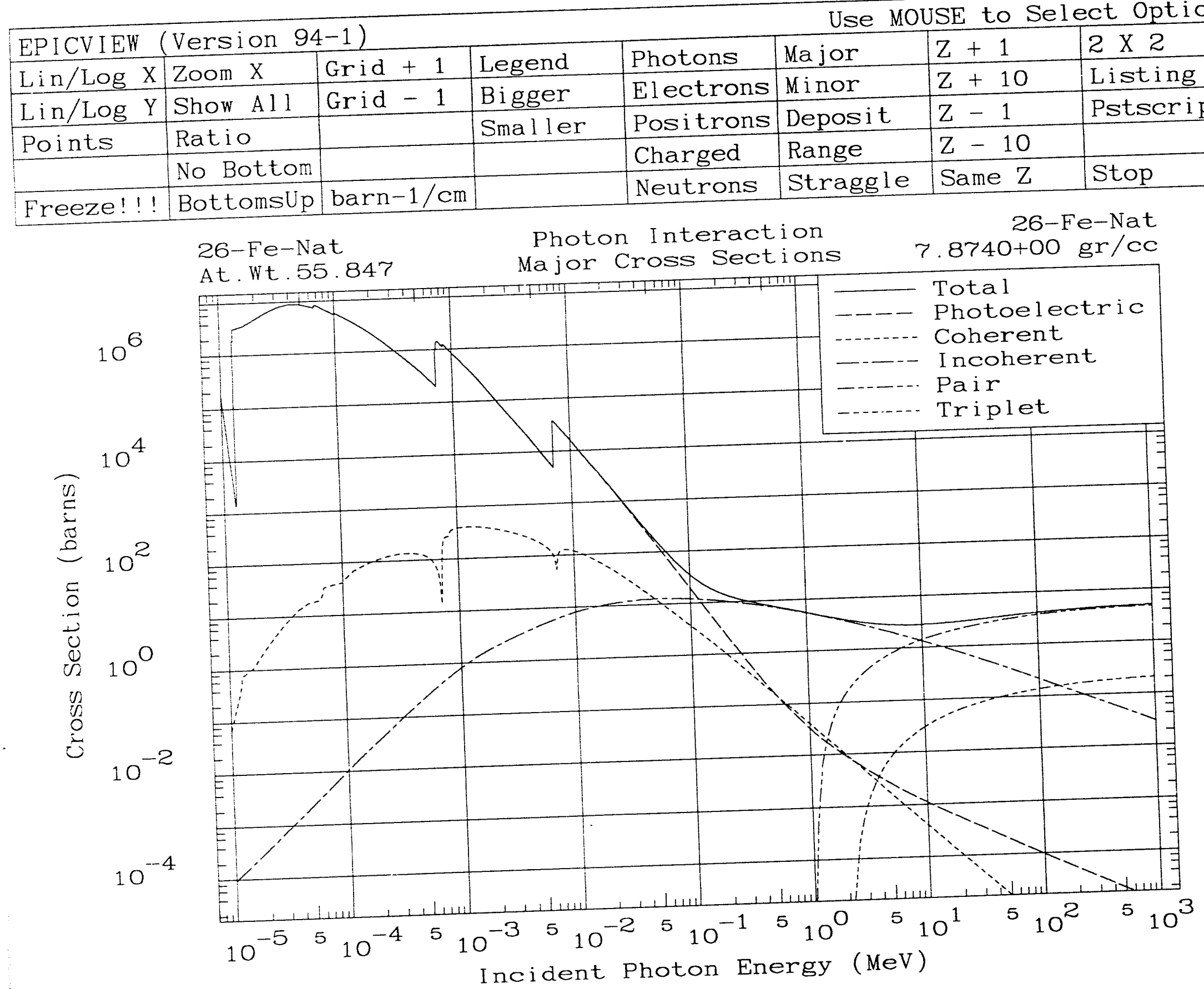




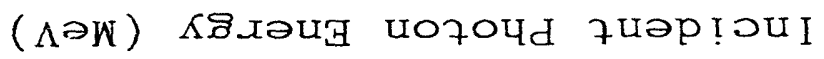

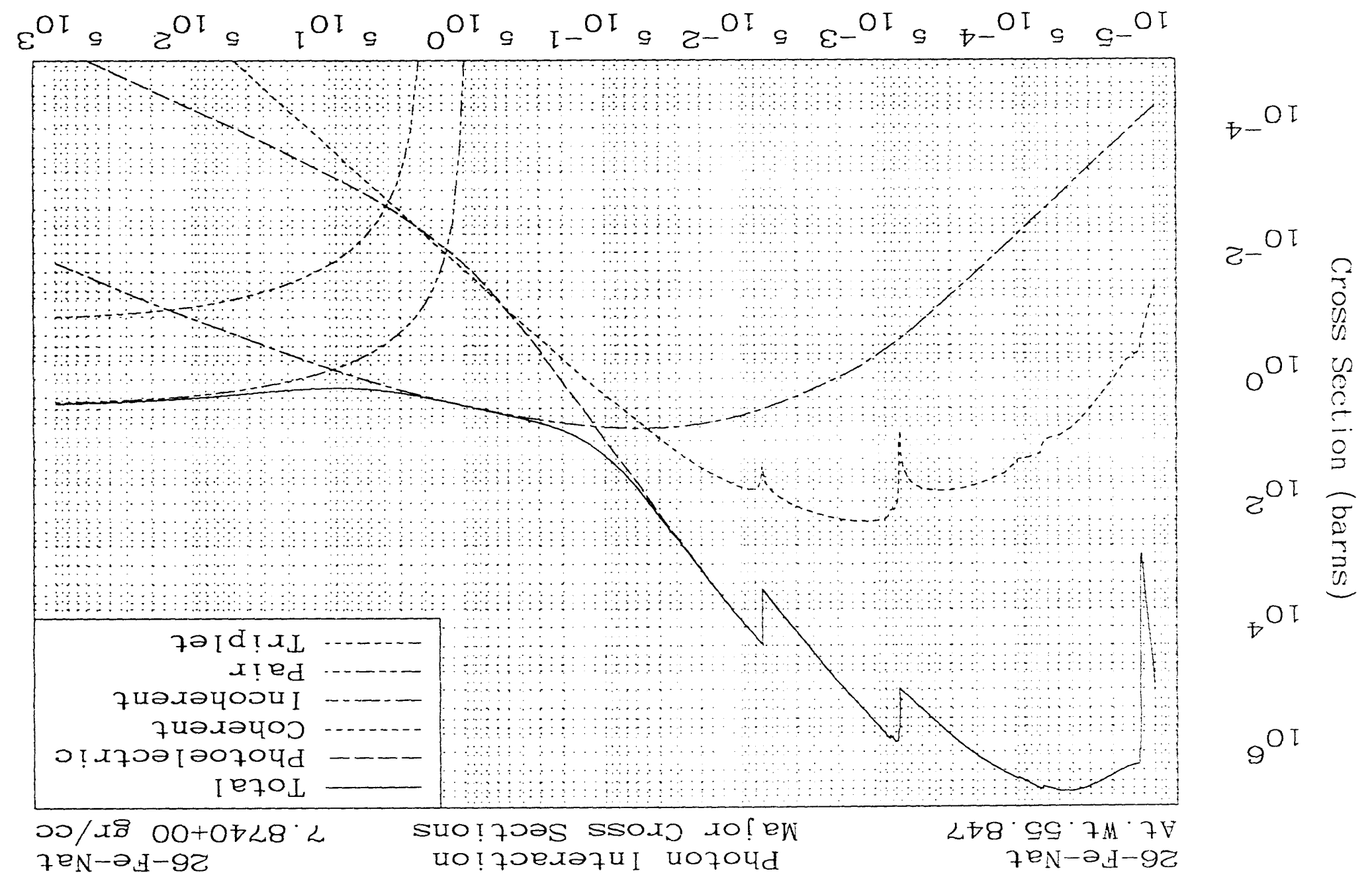

\begin{tabular}{|c|c|c|c|c|c|c|c|}
\hline do7s & $\mathrm{Z}$ owes & วI ถิธียxาS & SUOX $x$ nəN & & $\mathrm{mo} / \mathrm{I}-\mathrm{u} x \mathrm{xq}$ & dnsuo77og & i i iəzəəコ \\
\hline & $O I-Z$ & วชินeม & рәฮิхечว & & & wo770g ON & \\
\hline $7 d$ IJOS7sd & $I-Z$ & 7 ! sodəd & suoxt!sod & גəI I EUS & & o!fey & Sfu! od \\
\hline ชิน!7s!T & $\mathrm{OI}+\mathrm{Z}$ & גou!W & suox70aIH & มวดัด !ด & $I-P I x J$ & IIV MOUS & X OิOT/UIT \\
\hline z $\times 2$ & $I+Z$ & IO EN & su0704d & рนวठิวT & $I+P ! I J$ & $X$ woOZ & $\mathrm{X}$ వెంT/U TT \\
\hline Uo! 7 do 70 & O7 HS & $\partial S_{\Omega}$ & & & $(1-$ & 6 บO! Sגว $\Lambda$ & MGI $\Lambda \supset I d G$ \\
\hline
\end{tabular}




\begin{tabular}{|l|l|l|l|l|l|l|l|l|}
\hline EPICVIEW & \multicolumn{5}{c|}{ Use MOUSE to Select Option } \\
\hline Lin/Log X & Zoom X & Grid +1 & Legend & Photons & Major & $Z+1$ & 2 X 2 \\
\hline Lin/Log Y & Show All & Grid -1 & Bigger & Electrons & Minor & $Z+10$ & Listing \\
\hline Points & Ratio & & Smaller & Positrons & Deposit & $Z-1$ & Pstscript \\
\hline & No Bottom & & & Charged & Range & $Z-10$ & \\
\hline Freeze!!! & BottomsUp & barn-1/cm & & Neutrons & Straggle & Same Z & Stop \\
\hline
\end{tabular}

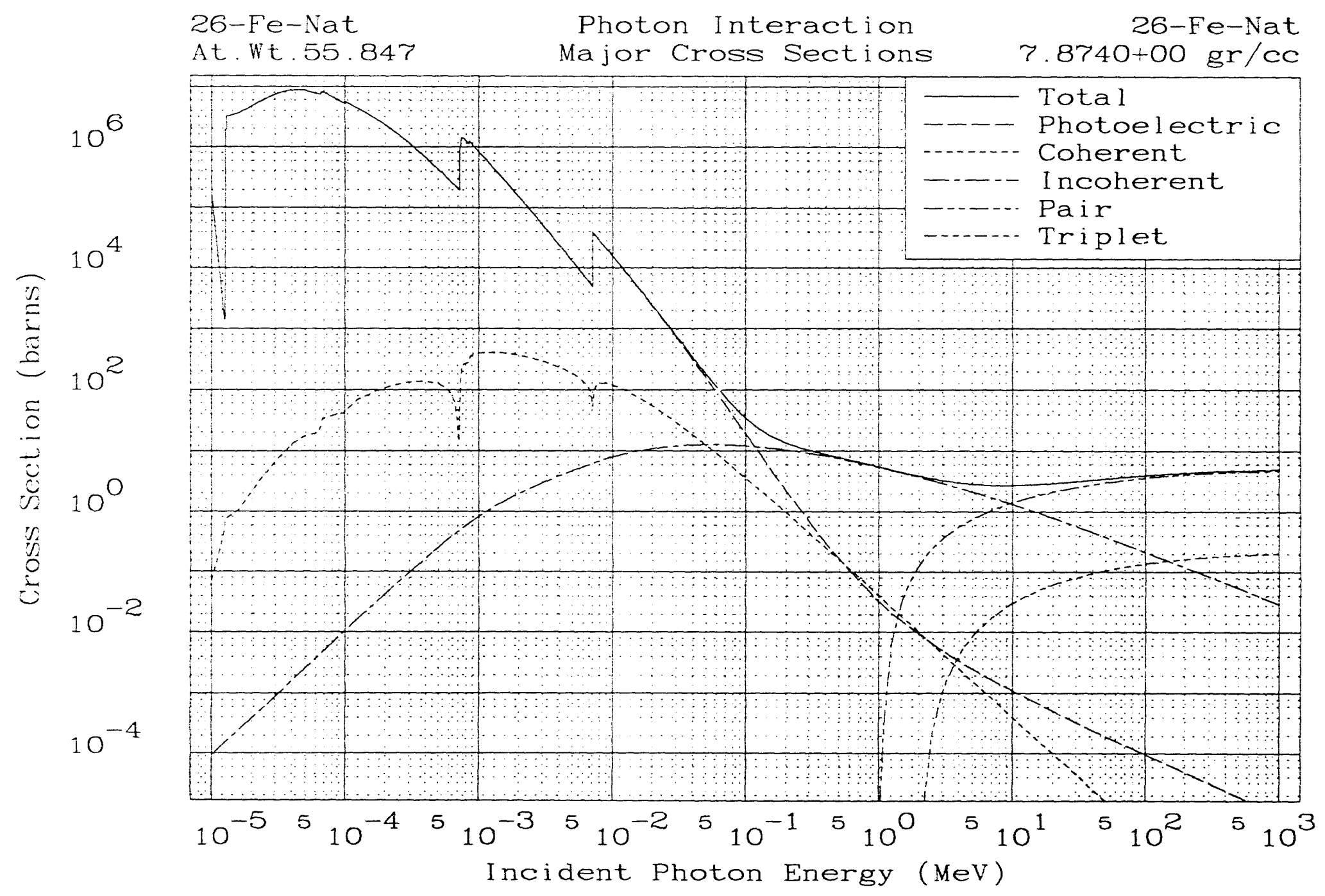




\begin{tabular}{|l|l|l|l|l|l|l|l|}
\hline EPICVIEW & Version 94-1) \\
\hline Lin/Log X & Zoom X & Grid +1 & Legend & Photons & Major & $Z+1$ & 2 X 2 \\
\hline Lin/Log Y & Show All & Grid -1 & Bigger & Electrons & Minor & $Z+10$ & Listing \\
\hline Points & Ratio & & Smaller & Positrons & Deposit & $Z-1$ & Pstscript \\
\hline & No Bottom & & & Charged & Range & $Z-10$ & \\
\hline Frcoze!!! BottomsUp barn-1/cm & & Neutrons & Straggle & Same Z & Stop \\
\hline
\end{tabular}

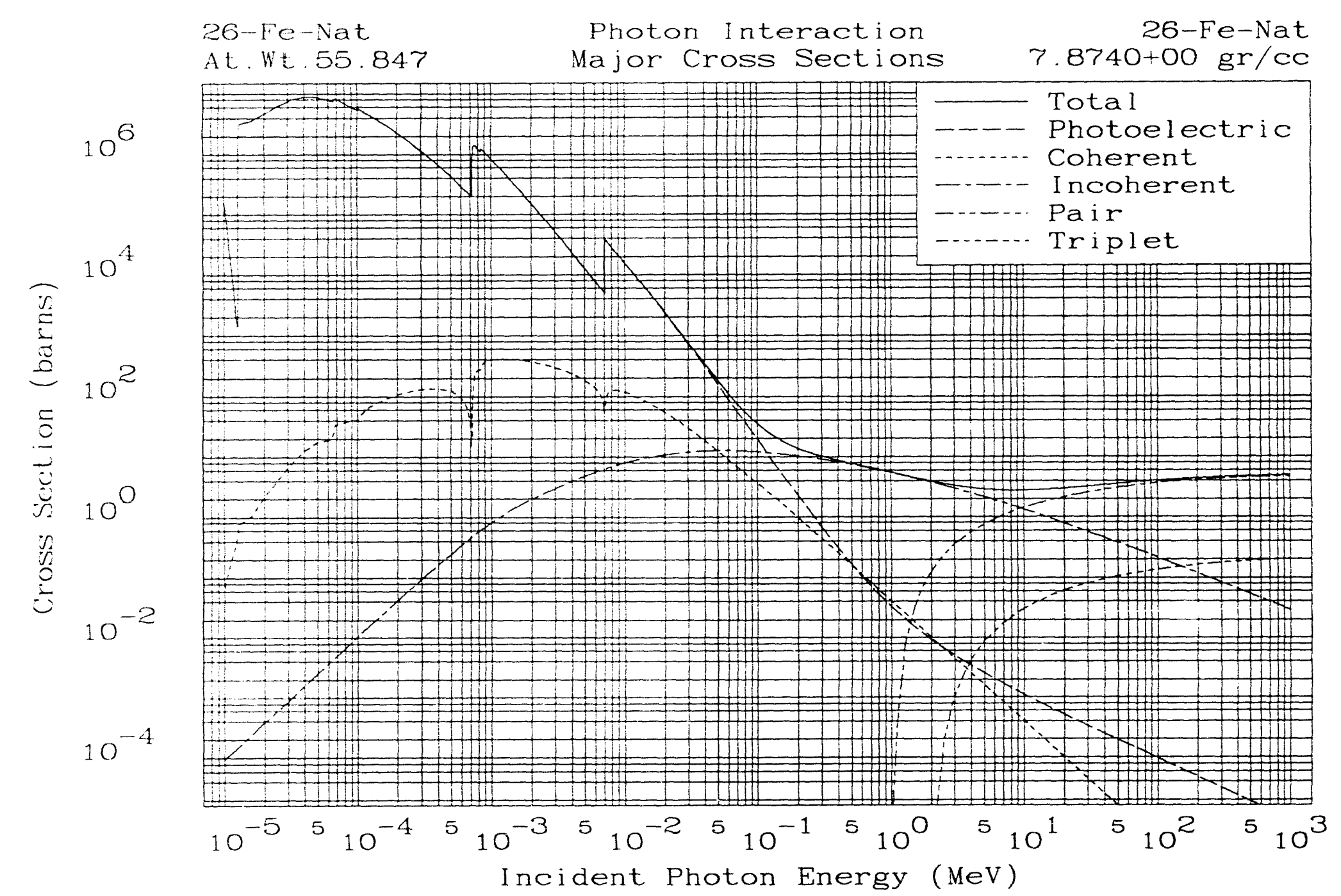




\section{4) $2 \times 2$}

This program can display either one full sized figure on the screen, or four half sized figures. The option $2 \times 2$ is useci :o change back and forth between one form and the other. The full sized figure will give you the best visual resolution, but the $2 \times 2$ half sized figures can be very useful for side by side comparisons of data.

The following figure illustrates the $2 \times 2$ mode, in this case to obtain a side by side comparison of the uranium photon and electron major cross sections (upper 2 plots) and energy deposition (lower 2 plots).

\section{5) Zoom $X$ and Show All}

The Zoom $\mathrm{X}$ option allows you to zoom in and look at any portion of a figure in more detail. Once you have selected this option you can use your mouse to indicate the lower and upper $X$ limits of the next figure; simply clock your mouse anywhere within the figure to select limits.

The Show All option allows you to un-do Zoom X: the next figure will be of the entire $x$ range.

16) Points

The Points option allow you to switch back and forth between showing and not showing the actual tabulated data points for each curve on the figures. 


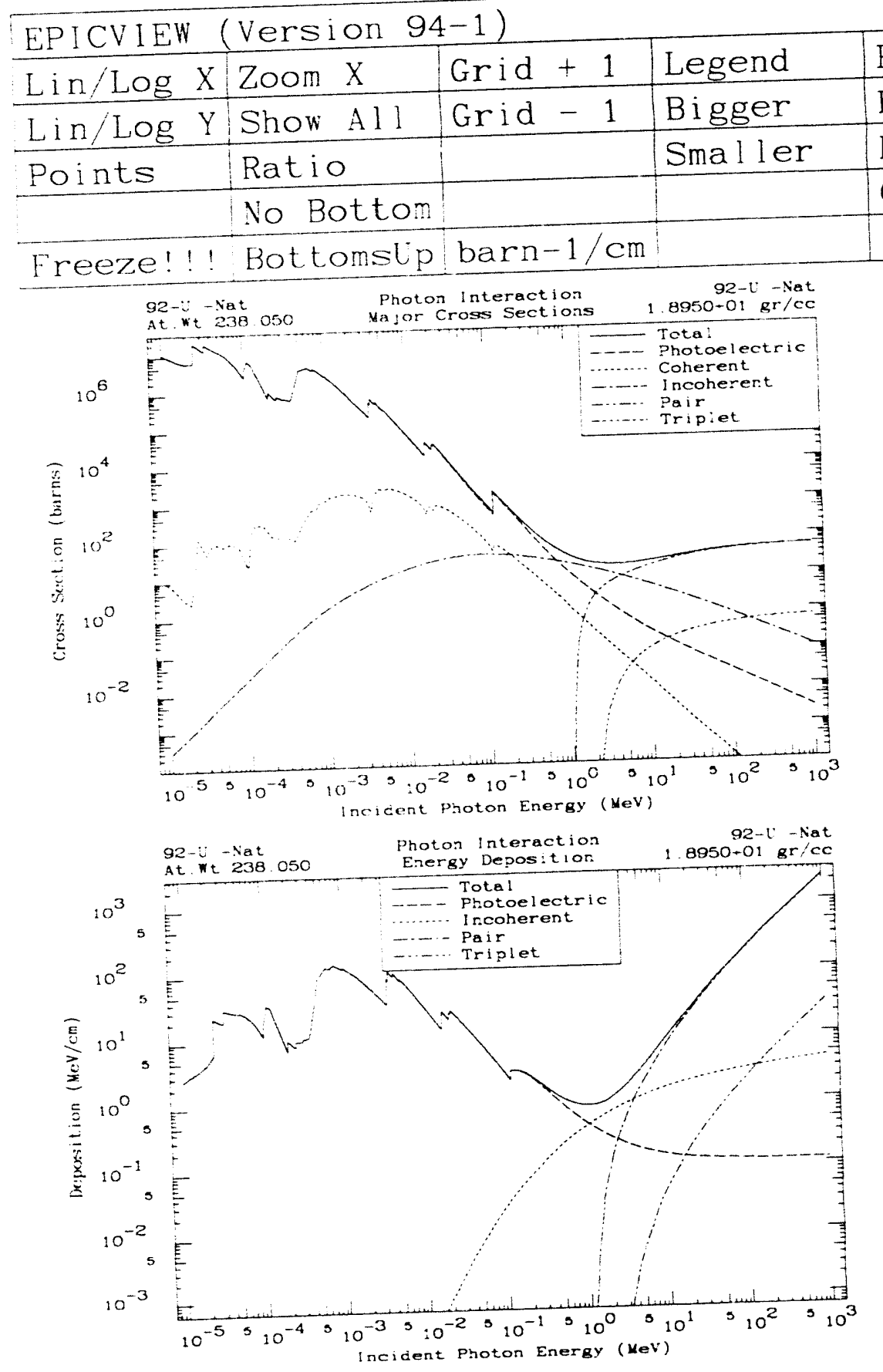

Use MOUSE to Select Option

\begin{tabular}{|l|l|l|l|}
\hline Photons & Ma jor & $Z+1$ & 2 X Z \\
\hline Electrons & Minor & $Z+10$ & Listing \\
\hline Positrons & Deposit & $Z-1$ & Pstscript \\
\hline Charged & Range & $Z-10$ & \\
\hline Neutrons & Straggle & Same Z & Stop \\
\hline
\end{tabular}

Neutrons S2-U -Nat
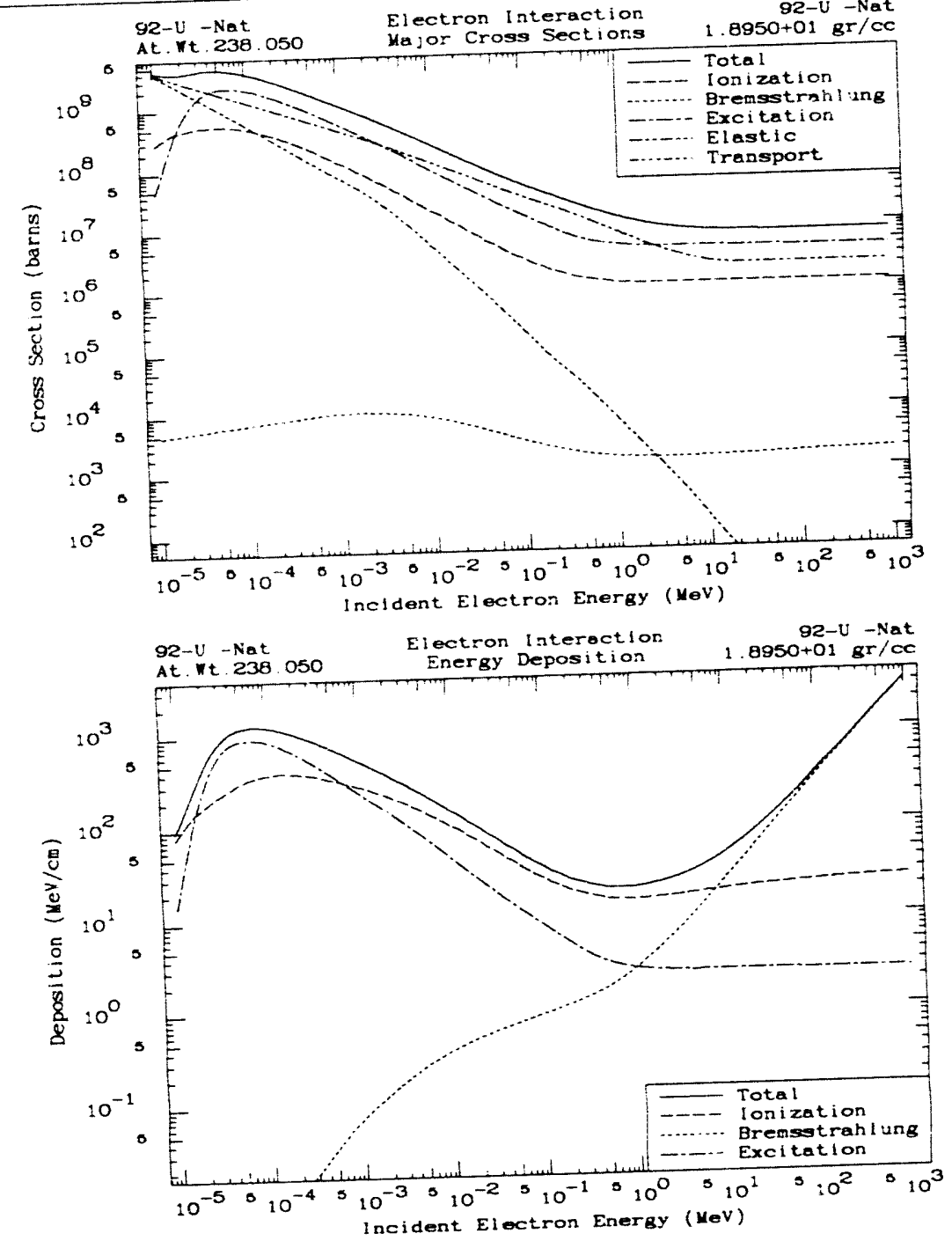
17) Ratio

The Ratio option allows you to switch back and forth between showing and not showing the ratio of all curves to the first curve.

The following figure illustrates the $2 \times 2$ option. With the first (upper, left hand) figure on the screen, I selected the Zoom $X$ option and used my mouse to select the energy (X) range $1 \mathrm{keV}$ to $500 \mathrm{keV}$ (indicated by the vertical lines on the figure). The result was the second (upper, right hand) figure, showing the energy range I selected. Next I selected the points option; the result was the third (lower. left hand) figure. Finally I selected the Freeze!!! option, selected the points option again (to turn off the points), selected Freeze!!! again and then Ratio. The result was the fourth (lower, right hand) figure showing the ratio of all the cross sections to the Total. 


\begin{tabular}{|c|c|c|c|c|c|c|c|}
\hline \multicolumn{8}{|c|}{ EPICVIEW (Version 94-1) } \\
\hline $\operatorname{Lin} / \log x$ & Zoom X & Grid + 1 & Legend & Photons & Ma jor & $Z+1$ & $2 \times 2$ \\
\hline $\operatorname{Lin} / \log Y$ & Show A I I & Grid -1 & Bigger & Electrons & Minor & $Z+10$ & Listing \\
\hline \multirow[t]{2}{*}{ Points } & Ratio & & Smaller & Positrons & Deposit & $Z-1$ & Pstscript \\
\hline & No Bottom & & & Charged & Range & $Z-10$ & \\
\hline Freeze!!! & BottomsUp & barn-1/cm & & Neutrons & Straggle & Same Z & Stop \\
\hline
\end{tabular}
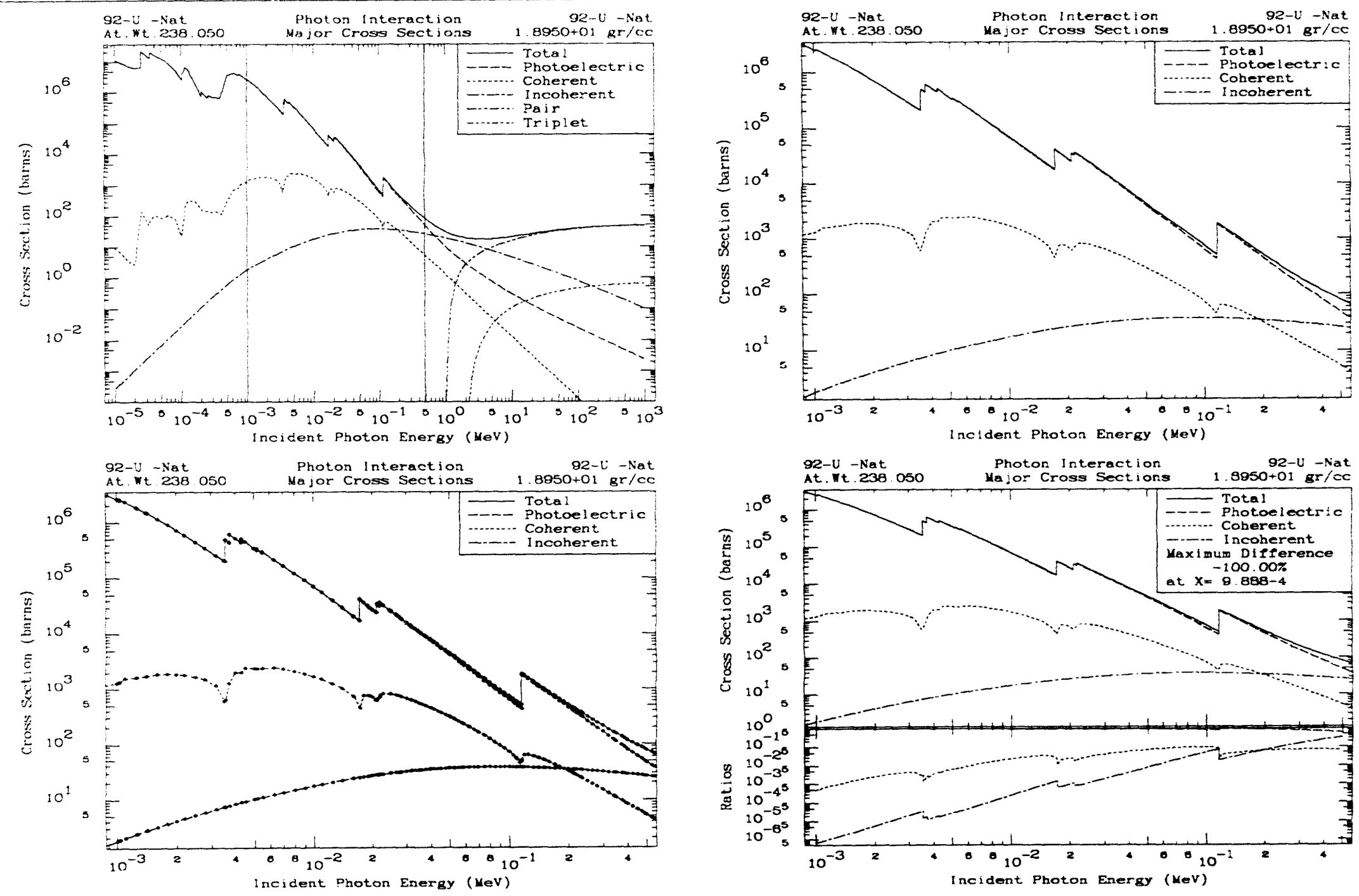
18) $\operatorname{Lin} / \log X$ and $Y:$ Linear or Log Scaling

When data is initially displayed the scaling is automatically selected by the program based on the $X$ and $Y$ ranges of the data; in most cases the initial plot will by $\log -\log$ scaled. The $\operatorname{Lin} / \log X$ and $\operatorname{Lin} / \log Y$ allow you to change the scaling to meet your needs. The following figure illustrates the aluminum charged particle energy deposition. The first (upper, left hand) figure is scaled log-log and is not the form in which this data is normally presented in publications. For the next (upper, right hand) figure I selected the Lin/Log $Y$ option to change the $Y$ scaling from log to linear to obtain results in a more familiar form that is seen in publication.

In the above case using a linear $Y$ scale yielded results in the form that we wanted them. The next two figures illustrate the importance of using the correct scaling. In this case the aluminum ranges are presented using both log and linear $Y$ scaling. In this case the linear Y scaling yields poor results, since we can hardly see anything.

19) barn-1/cm: Microscopic or Macroscopic

The barn-1/cm option switches back and forth between microscopic (barn) and macroscopic $(1 / \mathrm{cm})$ cross sections. The conversion from microscopic to macroscopic using the atomic weight and density listed at the top of each figure. The following figure illustrates the lead photon and electron major cross sections in microscopic and macroscopic form. 


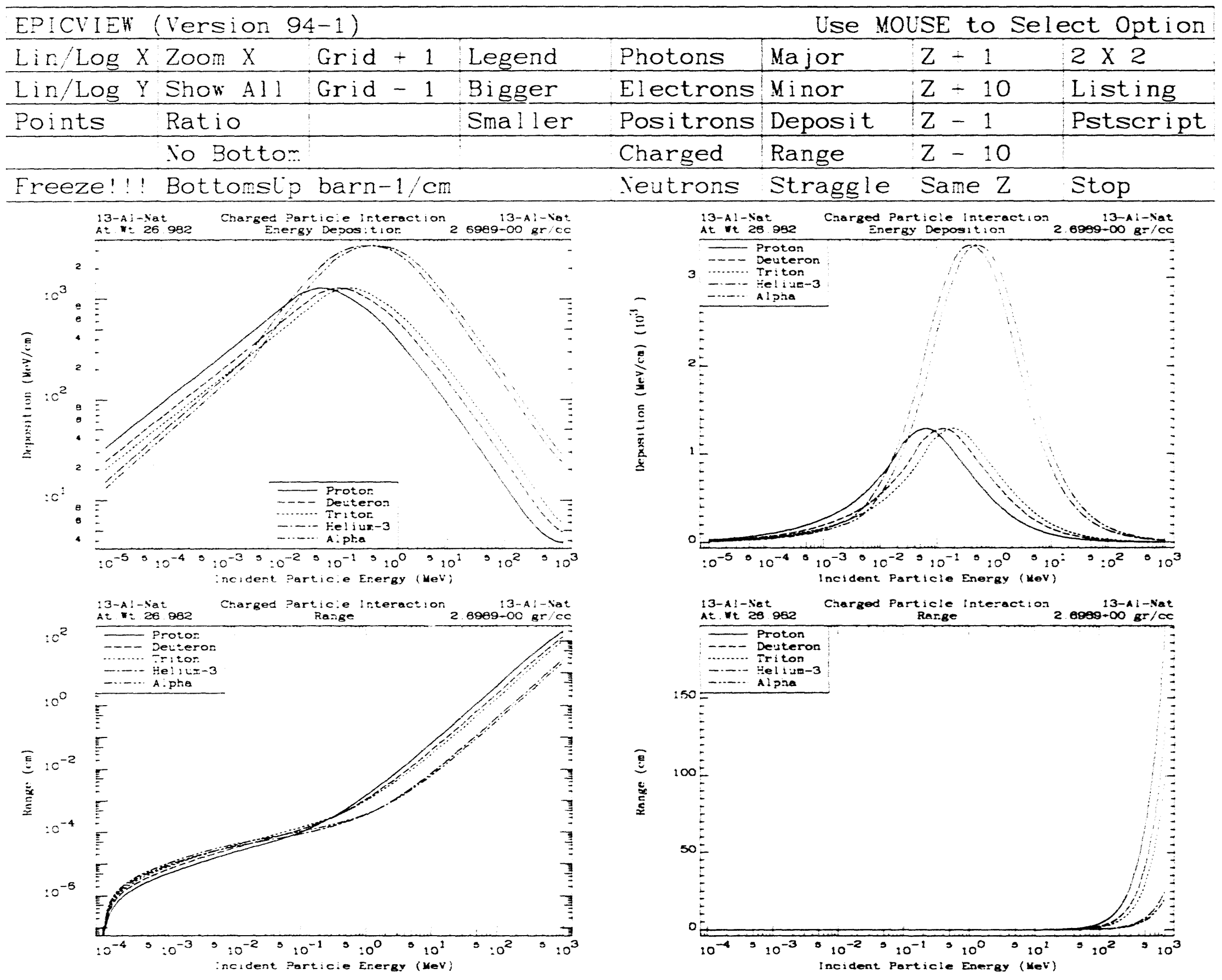




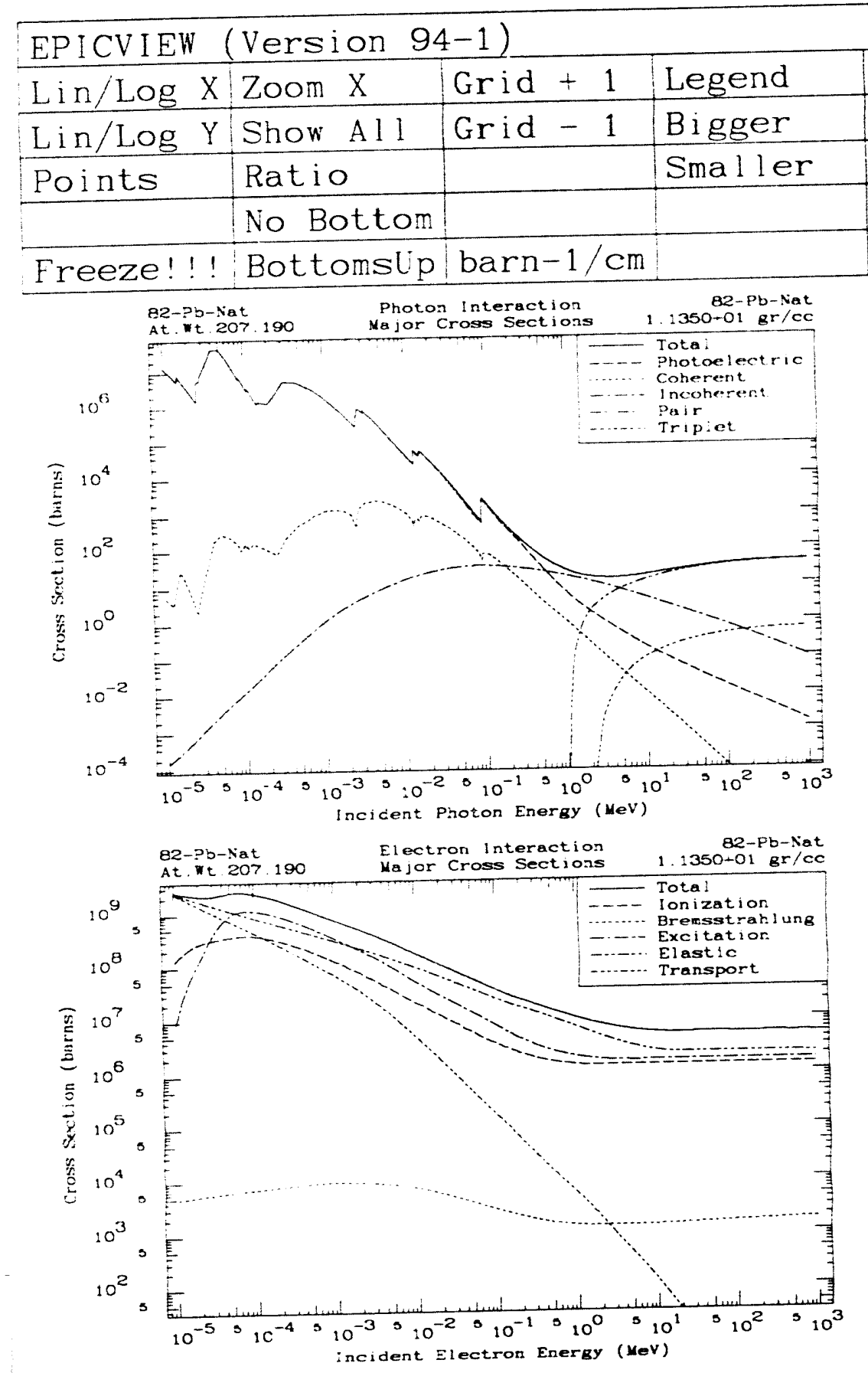

Use MOUSE to Select Option

\begin{tabular}{|l|l|l|l|}
\hline Photons & Ma jor & $Z+1$ & 2 X 2 \\
\hline Electrons & Minor & $Z+10$ & Listing \\
\hline Positrons & Deposit & $Z-1$ & Pstscript \\
\hline Charged & Range & $Z-10$ & \\
\hline Neutrons & Straggle & Same Z & Stop \\
\hline
\end{tabular}
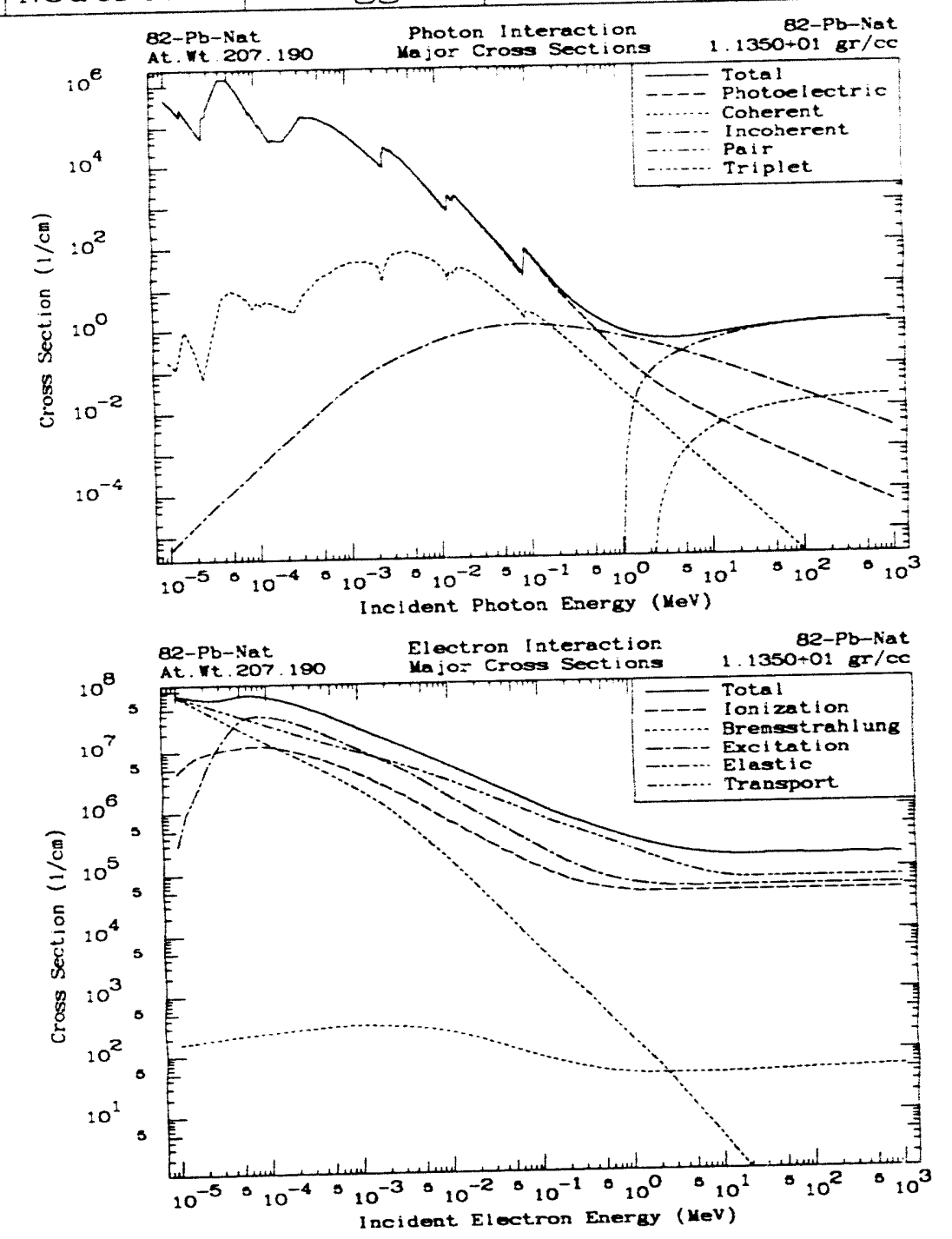


\section{0) Listing: Tabulated Output Listings}

The listing option allows you to obtain a tabulated listing of the data that you are currently viewing. For whatever combination of projectile and target that you are viewing ALL of the data is listed. For example, if I am currently viewing the lead photon data (any type of data - major, minor, etc.), when I select the Listing option the following illustrates a portion of the tabulated results that are written into the file EPICSHOW.LST. Three separate tables are produced: 1) major cross sections in barns and energy loss per collision in MeV, 2) photoelectric shell cross sections in barns, 3) derived quantities, such as mean free path and energy Ioss in $\mathrm{MeV} / \mathrm{cm}$ (these calculations use the atomic weight and the density listed at the top of each table). 
Energy Cross sections (barns) (MeV) Total photo. Coherent Incoher. Pair Triplet Photo. Incoher. Pair

$1.0000-051.4702+071.4702+075.7651+001.5580-04$ $1.2500-05 \quad 8.9032+06 \quad 8.9032+06 \quad 3.5860+00 \quad 2.4347-04$ $1.5050-05 \quad 5.5635+06 \quad 5.5635+06 \quad 3.0188+01 \quad 3.5432-04$

$1.5050-05 \quad 8.6140+06 \quad 8.6140+06 \quad 3.0188+01 \quad 3.5432-01$ $1.6000-05 \quad 6.9745+06 \quad 6.9745+06 \quad 2.5819+01 \quad 3.9896-04$ $2.0000-05 \quad 3.3958+06 \quad 3.3958+06 \quad 9.0781+00 \quad 6.2347-04$

$2.5000-05 \quad 1.6853+06 \quad 1.6853+06 \quad 2.0633+00 \quad 9.7432-04$

$2.6030-051.4983+06 \quad 1.4983+06 \quad 3.6550+00 \quad 1.0599-03$

$2.6030-05 \quad 5.1830+06 \quad 5.1830+06 \quad 3.6550+00 \quad 1.0599-03$

$2.8810-05 \quad 6.1801+06 \quad 6.1801+06 \quad 1.0208+01 \quad 1.2967-03$

$2.8810-05 \quad 8.1266+06 \quad 8.1266+06 \quad 1.0208+01 \quad 1.2967-03$

$3.2000-05 \quad 1.3278+07 \quad 1.3278+07 \quad 2.8643+01 \quad 1.5966-03$

$4.0000-05 \quad 4.4100+07 \quad 4.4100+07 \quad 1.9015+02 \quad 2.4950-03$

$5.0000-05 \quad 4.4341+07 \quad 4.4341+07 \quad 3.0861+02 \quad 3.8991-03$

$6.3000-05 \quad 2.2431+07 \quad 2.2431+07 \quad 2.6018+02 \quad 6.1911-03$

8.0000-05 $9.1335+06 \quad 9.1334+06 \quad 1.6883+02 \quad 9.9847-03$

$8.7640-05 \quad 6.2375+06 \quad 6.2374+06 \quad 1.0592+02 \quad 1.2005-02$

$8.7640-057.3704+067.3703+061.0592+021.2005-02$

$1.0000-04 \quad 4.5024+06 \quad 4.5023+06 \quad 1.5956+02 \quad 1.5603-02$

$\begin{array}{lllll}1.1091-04 & 2.9540+06 & 2.9539+06 & 1.2235+02 & 1.9163-02\end{array}$

$1.1091-043.5695+06 \quad 3.5694+06 \quad 1.2235+02 \quad 1.9163-02$

$\begin{array}{lllll}1.2500-04 & 2.2422+06 & 2.2421+06 & 1.6672+02 & 2.4255-02\end{array}$

$1.4781-041.2168+06 \quad 1.2167+06 \quad 1.3976+02 \quad 3.3899-02$

$1.4781-041.3559+06,1557+06 \quad 1.3976+02 \quad 3.3899-02$

$1.5283-04 \quad 1.2904+06 \quad 1.2903+06 \quad 1.3222+02 \quad 3.6211-02$

$1.5283-04 \quad 1.3495+061.3494+06 \quad 1.3222+02 \quad 3.6211-02$

$1.5304-04 \quad 1.3455+06 \quad 1.3453+06 \quad 1.3226+02 \quad 3.6308-02$

$1.5304-041.4518+061.4517+061.3226+02 \quad 3.6308-02$

$1.6000-041.4022+061.4021+061.3201+02 \quad 3.9513-02$

$2.0000-04 \quad 1.2509+06 \quad 1.2508+06 \quad 1.0351+02 \quad 6.1421-02$

$2.5000-04 \quad 2.3099+06 \quad 2.3098+06 \quad 8.1066+01 \quad 9.5475-02$

3.2000-04 $5.2457+06 \quad 5.2455+06 \quad 2.3151+02 \quad 1.5452-01$

$4.0000-04 \quad 5.1061+06 \quad 5.1057+06 \quad 3.6998+02 \quad 2.3796-01$

$4.1249-04 \quad 5.0112+06 \quad 5.0108+06 \quad 3.8864+02 \quad 2.5280-01$

$4.1249-04 \quad 5.1224+06 \quad 5.1220+06 \quad 3.8864+02 \quad 2.5280-01$

$4.3523-04 \quad 5.0475+06 \quad 5.0470+06 \quad 4.5458+02 \quad 2.8049-01$

$4.3523-045.1364+06 \quad 5.1359+06 \quad 4.5458+02 \quad 2.8049-01$

$5.0000-04 \quad 4.6457+06 \quad 4.6451+06 \quad 5.9635+02 \quad 3.6299-01$

$6.3000-04 \quad 3.4769+06 \quad 3.4762+06 \quad 7.2803+02 \quad 5.5594-01$

$6.3430-04 \quad 3.4464+06 \quad 3.4456+06 \% .5701+02 \quad 5.6300-01$

$6.3430-04 \quad 3.6504+06 \quad 3.6496+06 \% .5701+02 \quad 5.6300-01$

$7.5602-04 \quad 2.8225+06 \quad 2.8215+06 \quad 1.0123+03 \quad 7.7119-01$

$7.5602-04 \quad 2.8605+06 \quad 2.8595+06 \quad 1.0123+03 \quad 7.7119-01$

$8.0000-042.5821+06 \quad 2.5810+06 \quad 1.0757+03 \quad 8.4848-01$

$8.7672-042.2212+06 \quad 2.2200+06 \quad 1.1320+03 \quad 9.9094-01$

$8.7672-042.2641+062.2629+061.1320+03 \quad 9.9094-01$
$6.1528-062.7402-10$

$8.6876-061.0275-09$

1. $1149-051.8306-09$

$1.2531-051.8306-09$

$1.3477-052.0825-09$

$1.7185-05 \quad 3.2881-09$

$2.1963-05 \quad 4.7952-09$

$2.2875-055.1605-09$

2.5118-05 5.1605-09

$2.8246-05 \quad 5.9802-09$

$2.8381-05 \quad 5.9802-09$

$3.1808-05 \quad 6.9051-09$

$3.9969-05 \quad 9.3164-09$

$4.9984-05 \quad 1.2330-08$

$6.2983-051.6219-08$

$7.9978-052.1373-08$

$8.7284-05 \quad 2.3767-08$

$8.7339-05 \quad 2.3767-08$

9.9974-05 2.7401-08

1. $1048-043.8697-08$

$1.1055-04 \quad 3.8697-08$

1.2497-04 5.2897-08

$1.4715-047.7238-08$

1. 4722-04 7.7238-08

1. $5240-048.2340-08$

1. $52.42-048.2340-08$

$1.5265-04 \quad 8.2539-08$

1. 5268-04 8.2539-08

1.5996-04 8.8591-08

1. $9997-041.2939-07$

2. 4998-04 1.8038-07

3.1999-04 2.9286-07

3.9999-04 4.4566-07

4.1197-04 4.7120-07

4.1198-04 4.7120-07

$4.3490-04 \quad 5.2532-07$

4. 3491-04 5.2532-07

4. 9999-04 6.9395-07

6.2999-04 1.0898-06

6.3370-04 1.1078-06

$6.3373-04 \quad 1.1078-06$

$7.5035-041.5437-06$

7. 5042-04 1.5437-06

7.9998-04 1.7384-06

8. 7519-04 2.1028-06

$8.7522-042.1028-06$ 


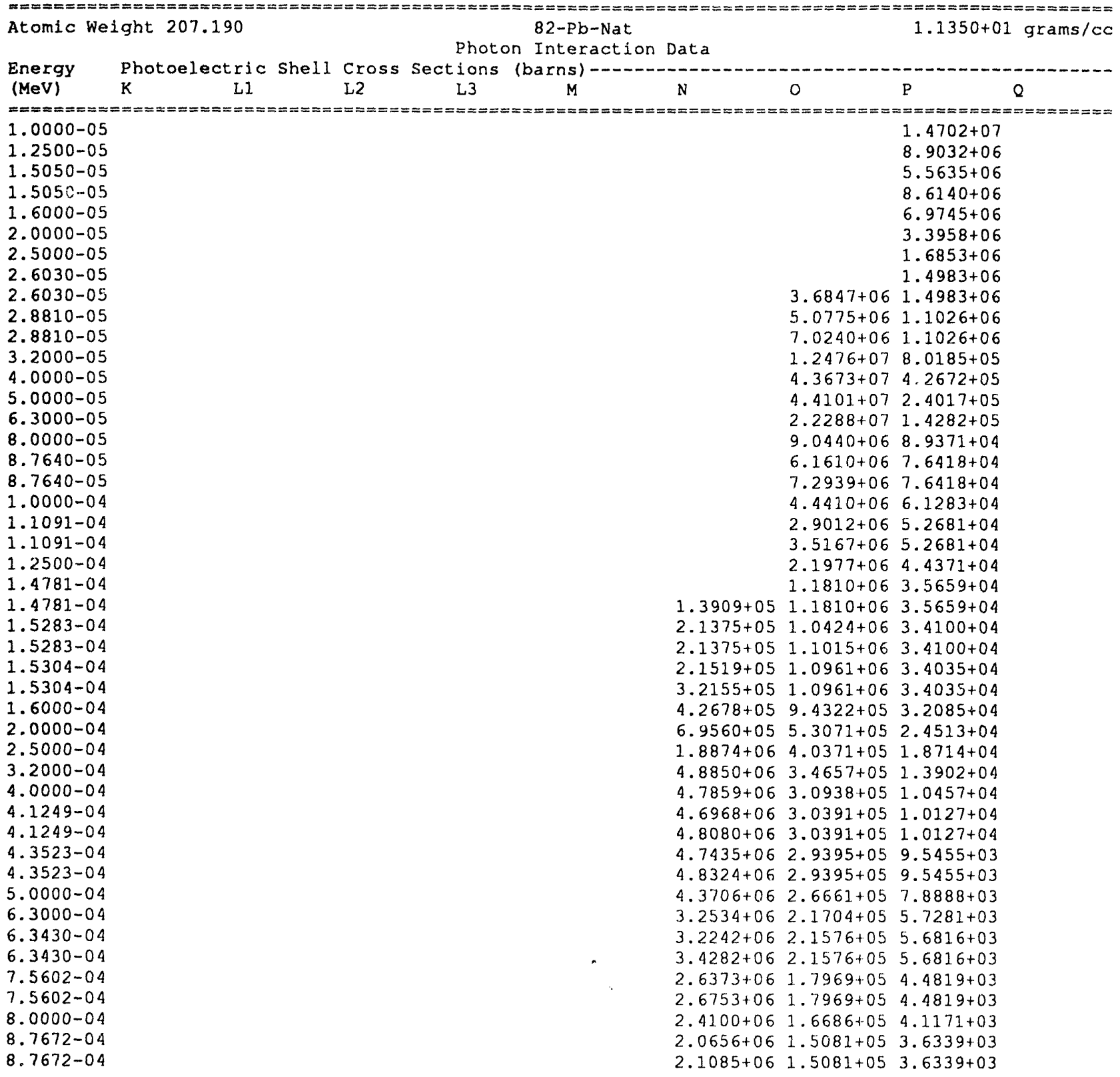




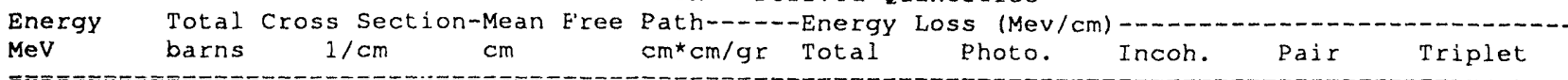

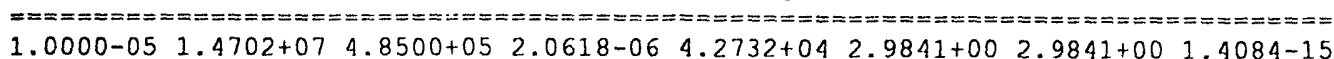

$\begin{array}{llllllll}1.2500-05 & 8.9032+06 & 2.9371+05 & 3.4048-06 & 2.5877+04 & 2.5516+00 & 2.5516+00 & 8.2527-15\end{array}$

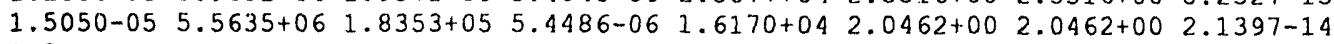

$1.5050-05 \quad 8.6140+06 \quad 2.8417+05 \quad 3.5191-06 \quad 2.5037+04 \quad 3.5609+00 \quad 3.5609+00 \quad 2.1397-14$

$1.6006-05 \quad 6.9745+06 \quad 2.3008+05 \quad 4.3463-06 \quad 2.0272+04 \quad 3.1008+00 \quad 3.1008+00 \quad 2.7408-14$

$\begin{array}{llllllll}2.0000-05 & 3.3958+06 & 1.1202+05 & 8.9267-06 & 9.8700+03 & 1.9251+00 & 1.9251+00 & 6.7628-14\end{array}$

$2.5000-05 \quad 1.6853+06 \quad 5.5596+04 \quad 1.7987-05 \quad 4.8983+03 \quad 1.2211+001.2211+00 \quad 1.5413-13$

$2.6030-05 \quad 1.4983+06 \quad 4.9427+04 \quad 2.0232-05 \quad 4.3548+03 \quad 1.1306+00 \quad 1.1306+00 \quad 1.8044-13$

$2.6030-05 \quad 5.1830+06 \quad 1.7098+05 \quad 5.8486-06 \quad 1.5064+04 \quad 4.2947+004.2947+00 \quad 1.8044-13$

$2.8810-05 \quad 6.1801+06 \quad 2.0388+05 \quad 4.9050-06 \quad 1.7963+04 \quad 5.7586+00 \quad 5.7586+00 \quad 2.5581-13$

$2.8810-05 \quad 8.1266+06 \quad 2.6809+05 \quad 3.7301-06 \quad 2.3620+04 \quad 7.6086+00 \quad 7.6086+00 \quad 2.5581-13$

$\begin{array}{llllllllll}3.2000-05 & 1.3278+07 & 4.3802+05 & 2.2830-06 & 3.8592+04 & 1.3933+01 & 1.3933+01 & 3.6369-13\end{array}$

4.0000-05 $4.4100+071.4548+06 \quad 6.8738-07 \quad 1.2818+05 \quad 5.8147+015.8147+01 \quad 7.6681-13$

$\begin{array}{lllllllll}5.0000-05 & 4.4341+07 & 1.4628+06 & 6.8363-07 & 1.2888+05 & 7.3115+01 & 7.3115+01 & 1.5860-12\end{array}$

$\begin{array}{llllllllll}6.3000-05 & 2.2431+07 & 7.3998+05 & 1.3514-06 & 6.5196+04 & 4.6605+01 & 4.6605+01 & 3.3187-12\end{array}$

8.0000-05 $9.1335+06 \quad 3.0131+05 \quad 3.3189-06 \quad 2.6547+04 \quad 2.4097+01 \quad 2.4097+01 \quad 7.0399-12$

$\begin{array}{llllllllll}8.7640-05 & 6.2375+06 & 2.0577+05 & 4.8598-06 & 1.8129+04 & 1.7960+01 & 1.7960+01 & 9.4125-12\end{array}$

8.7640-05 $7.3704+06 \quad 2.4314+05 \quad 4.1128-06 \quad 2.1422+04 \quad 2.1235+012.1235+01 \quad 9.4125-12$

1.0000-04 4.5024+06 $1.4853+05 \quad 6.7326-06 \quad 1.3086+04 \quad 1.4849+01 \quad 1.4849+01 \quad 1.4104-11$

1.1091-04 2.9540+06 $9.7449+04 \quad 1.0262-05 \quad 8.5858+03 \quad 1.0766+01 \quad 1.0766+01 \quad 2.4463-11$

1.1091-04 3.5695+06 $1.1775+05 \quad 8.4923-06 \quad 1.0375+04 \quad 1.3017+01 \quad 1.3017+012.4463-11$

$\begin{array}{llllllll}1.2500-04 & 2.2422+06 & 7.3969+04 & 1.3519-05 & 6.5171+03 & 9.2432+00 & 9.2432+00 & 4.2325-11\end{array}$

$1.4781-041.2168+06 \quad 4.0141+04 \quad 2.4912-05 \quad 3.5366+03 \quad 5.9060+00 \quad 5.9060+00 \quad 8.6375-11$

$\begin{array}{lllllllll}1.4781-04 & 1.3559+06 & 4.4729+04 & 2.2357-05 & 3.9409+03 & 6.5844+00 & 6.5844+00 & 8.6375-11\end{array}$

$\begin{array}{llllllll}1.5283-04 & 1.2904+06 & 4.2568+04 & 2.3492-05 & 3.7505+03 & 6.4867+00 & 6.4867+00 & 9.8360-11\end{array}$

$\begin{array}{lllllllll}1.5283-04 & 1.3495+06 & 4.4518+04 & 2.2463-05 & 3.9223+03 & 6.7848+00 & 6.7848+00 & 9.8360-11\end{array}$

$\begin{array}{lllllllll}1.5304-04 & 1.3455+06 & 4.4385+04 & 2.2530-05 & 3.9106+03 & 6.7747+00 & 6.7747+00 & 9.8862-11\end{array}$

$\begin{array}{llllllll}1.5304-04 & 1.4518+06 & 4.7894+04 & 2.0880-05 & 4.2197+03 & 7.3118+00 & 7.3118+00 & 9.8862-11\end{array}$

$1.6000-04 \quad 1.4022+06 \quad 4.6258+04 \quad 2.1618-05 \quad 4.0756+03 \quad 7.3987+00 \quad 7.3987+00 \quad 1.1548-10$

$\begin{array}{lllllllll}2.0000-04 & 1.2509+06 & 4.1267+04 & 2.4233-05 & 3.6358+03 & 8.2514+00 & 8.2514+00 & 2.6217-10\end{array}$

$2.5000-04 \quad 2.3099+06 \quad 7.6201+04 \quad 1.3123-05 \quad 6.7138+03 \quad 1.9048+01 \quad 1.9048+01 \quad 5.6813-10$

3.2000-04 $5.2457+06 \quad 1.7305+05 \quad 5.7787-06 \quad 1.5247+04 \quad 5.5372+01 \quad 5.5372+01 \quad 1.4928-09$

4.0000-04 $5.1061+06 \quad 1.6844+05 \quad 5.9367-06 \quad 1.4841+04 \quad 6.7371+01 \quad 6.7371+01 \quad 3.4984-09$

$4.1249-04 \quad 5.0112+06 \quad 1.6531+05 \quad 6.0491-06 \quad 1.4565+04 \quad 6.8099+016.8099+01 \quad 3.9296-09$

$\begin{array}{lllllllll}4.1249-04 & 5.1224+06 & 1.6898+05 & 5.9177-06 & 1.4888+04 & 6.9612+01 & 6.9612+01 & 3.9296-09\end{array}$

4.3523-04 5.0475+06 $1.6651+05 \quad 6.0057-06 \quad 1.4670+04 \quad 7.2409+01 \quad 7.2409+01 \quad 4.8608-09$

$\begin{array}{lllllllll}4.3523-04 & 5.1364+06 & 1.6944+05 & 5.9017-06 & 1.4929+04 & 7.3686+01 & 7.3686+01 & 4.8608-09\end{array}$

$\begin{array}{lllllllll}5.0000-04 & 4.6457+06 & 1.5326+05 & 6.5250-06 & 1.3503+04 & 7.6617+01 & 7.6617+01 & 8.3098-09\end{array}$

$6.3000-04 \quad 3.4769+06 \quad 1.1470+05 \quad 8.7185-06 \quad 1.0106+04 \quad 7.2244+01 \quad 7.2244+01 \quad 1.9987-08$

$6.3430-04 \quad 3.4464+06 \quad 1.1369+05 \quad 8.7956-06 \quad 1.0017+04 \quad 7.2031+01 \quad 7.2031+01 \quad 2.0575-08$

$6.3430-04 \quad 3.6504+06 \quad 1.2042+05 \quad 8.3041-06 \quad 1.0610+04 \quad 7.6300+01 \quad 7.6300+01 \quad 2.0575-08$

$\begin{array}{lllllllll}7.5602-04 & 2.8225+06 & 9.3111+04 & 1.0740-05 & 8.2036+03 & 6.9841+01 & 6.9841+01 & 3.9273-08\end{array}$

$\begin{array}{lllllllll}7.5602-04 & 2.8605+06 & 9.4364+04 & 1.0597-05 & 8.3140+03 & 7.0788+01 & 7.0788+01 & 3.9273-08\end{array}$

$8.0000-04 \quad 2.5821+06 \quad 8.5179+04 \quad 1.1740-05 \quad 7.5048+03 \quad 6.8113+01 \quad 6.8113+01 \quad 4.8659-08$ 


\section{1) Pstscript: Postscript Output}

The Postscript option allows you to obtain hardcopy graphics output. All of the figures included in this report were produced using this option.

The program starts with the option turned off. Once this option is selected, to turn on postscript output, the program will continue to produce postscript output of everything that appears on your screen, until this option is selected again, to turn off postscript output.

WARNING - producing postscript files is time consuming and will greatly slow down the execution of the program. Therefore you should only use this option if you really need hardcopy output.

See the section on routine files to your local printer to understand how to route the standard files produced by this program to your local printer.

A number of options have been added to meet the needs of individual graphics systems. These include,

\section{2) Legend}

Each plot will normally contain a legend box identifying each curve that is shown on the plot. The Legend option allows you to switch between showing and not showing the legend box. Once you become familiar with the type of data being displaying you may not need the legend box, and visual resolution of the data can be improved by removing it from the screen. 


\section{3) Bigger and Smaller: Character Size}

The Bigger and Smaller options allow you to change the size of all characters displayed on the plots - NOT in the menu boxes; these are fixed - only those around the plot. On low resolution screens you can use the Larger option if the characters are not clear. On high resolution screens you can use the smaller option to make all characters smaller, thereby leaving more area of the screen available to resolve the actual data.

\section{4) Bottoms Up and No Bottom}

Some X-Windows systems insist upon using the bottom of the screen to identify each window. This identification can overlay the $\mathrm{X}$ axis labels and make it impossible to properly identify the data that you are viewing. Each time that the BottomsUp option is selected the lower limit of the plot is moved up $1 / 2$ "; if you have the problem described above, this option will allow you to eliminate it. No Bottom disables the BottomsUp option for the remainder of your run; this has been included as a safeguard, so that once you have used BottomsUp to properly size your screen, if you later inadvertently select BottomsUp nothing will happen, if you have disabled it by selecting No Bottom. Note, No Bottom does not switch the BottomsUp option on and off - it absolutely shuts off BottomsUp for the entire remainder of your run. 
25) Interpolation of Data

All of the data in these data bases are in simple tabulated form where the tabulated energies have been selected to allow linear interpolation to any energy between the tabulated energies.

WARNING - if you use the Listing option or any other means to obtain data from this system for use in any application, in order to obtain reasonable results it is imperative that you interpolate the data exactly as it was intended to be interpolated = only use linear interpolation.

26) Availability

Epicshow is currently being made available to data and transpori experts throughout the world who are reviewing all of the EPIC data. Once this review phase is over and the data libraries updated to reflect all of the feedback, this code will be made available to all potential users.

27) Using your mouse

Epicshow avoids using any mickey mouse tricks that you would have to remember if the different buttons on a mouse served different purposes. To select an option press any button on your mouse; they are all treated as identical. 
28) Size of Data Bases

Currently the original data bases in character form are about 4 megabytes each for photons, electrons, positrons and neutrons and about 2 megabytes for the charged particles.

When converted to binary form for use in applications each of the data bases is roughly half the size of the corresponding character files.

For use on individual computers these binary files are distributed in compressed form, which again halves the size of each file.

In summary, to distribute the binary files requires roughly

4 1/2 megabytes of disk storage and to uncompress and use them roughly 9 megabytes of disk storage. 
29) Epicshow's Standard Graphic Interface

This program comes with standard graphics interfaces for use on IBM-PCs, or compatibles, and SUN X-Windows terminals, or compatibles.

For use on other computers you must supply the graphics interface for this code.

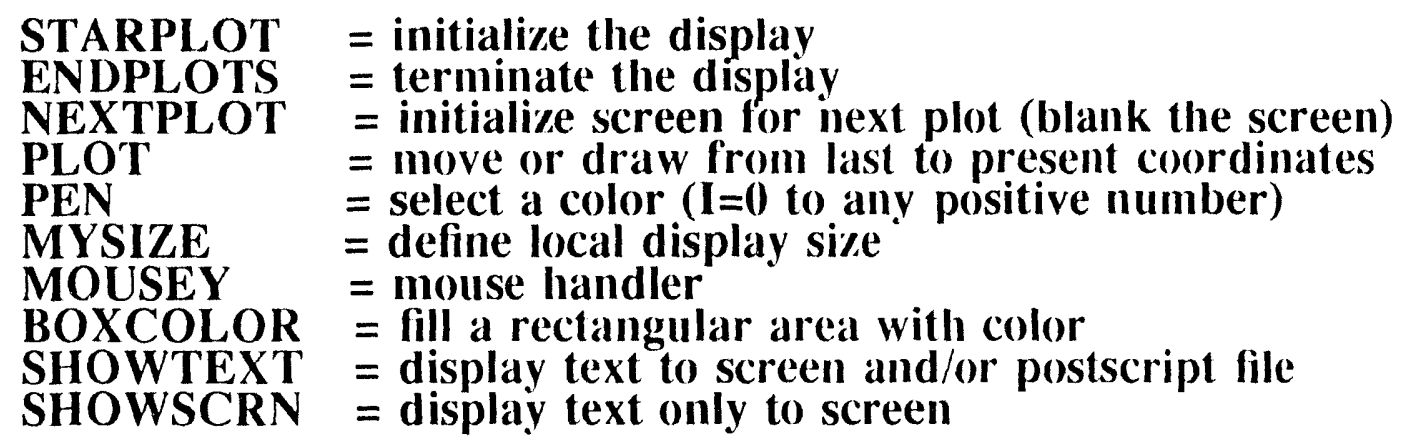

All of these are subroutine calls. STARPLOT, ENDPLOTS and NEXTPLOT have no arguments. The arguments for the others are,

$$
\begin{aligned}
& \text { PLOT(X,Y,I) } \\
& \begin{aligned}
I & =2 \text { - draw to }(X, Y) \\
& =3 \text { - move to }(X, Y)
\end{aligned}
\end{aligned}
$$

PEN(I)

$I=0$ to any positive integer (defines the color of all graphics that follows)

MYSIZE(XS,YS)

DIMENSION XS(2), YS(2) returned defining the lower and upper $X$ and $Y$ dimensions of your screen

$$
\begin{aligned}
& \text { MOUSEY(MS,XS, YS,MS1,MS2) } \\
& \begin{aligned}
\text { MS } & =\text { no mouse or keyboard input } \\
& =1 \text { to } 3 \text { = mouse hit } \\
& =4 \text { = keyboard } \\
\text { XS,YS } & =\text { coordinates of mouse hit } \\
\text { MS1,MS2 } & =\text { the returned value of MS must be in the } \\
\text { MS1 } & =0 \text { range MS1 to MS2 } \\
& =1 \text { allow return if no input } \\
& =4 \text { wait for mouse input } \\
\text { MS2 } & =4 \text { = wait only for keyboard input } \\
& =1 \text { to } 3 \text { = wait for mouse input } \\
& =4 \text { = wait only for keyboard input }
\end{aligned}
\end{aligned}
$$




$$
\begin{aligned}
& \text { BOXCOLOR(XB,YB,IFILL,IBORDER) } \\
& \text { DIMENSION XB(2),YB(2) define } \\
& \text { the X and Y limits of the rectangle } \\
& \begin{aligned}
\text { IFILL } & =\text { color to fill interior } \\
\text { IBORDER } & =-1 \text { none } \\
& =-1 \text { color of border } \\
& =-1 \text { none }
\end{aligned}
\end{aligned}
$$

SHOWTEXT(NX,NY,TEXT,NTEXT)

CHARACTER*1 TEX T(NTEXT) is the character string to be displayed

$$
\begin{array}{ll}
\text { NX } & =\text { columm - } 1 \text { to } 80 \\
\text { NY } & =\text { line () (top) to } 29 \text { (bottom) }
\end{array}
$$

\section{SHOWSCRN(NX,NY,TEX'T,NTEXT)}

a copy of SHOW'TEXT, but output only to the display (no Postscript)

\section{0) Postscript Output to Local Printer}

When producing Postscript formatted output this program writes into a file named PLOTTAB.PIT. When each plot is finished the program does a system call,

\section{CALI, SYSTEM('sendplot')}

to execute a file named sendplot. This file must direct PLOTTAB.PLT to your local Postscript printer. The actual contents of this file will vary from computer to computer, but generally it is merely a single line, as you would type it on your keyboard to direct a file to your printer. For example, on a SUN workstation, sendplot is an executable file containing the following single line, Ipr -h PLOTTAB.PLT 
WARNING - most printers will make a copy of PLOT'TAB.PLT and place it in a queue to be printed, or delay until printing is completed. Either of these approaches will work with this code. However, you should be aware that immediately after the system call this program will start writing the next Postscript plot into PLOTTAB.PL'T, so that you must not use a symbolic link or anything else that will cause your printer to directly reference and read PLOTTAB.PL'T while it is printing - if you do, the file will be changing while your printer is trying to print it.

31) Acknowledgements

I thank Ted Perkins who volunteered to play guinea pig to test the early versions of Epicshow and who made many useful suggestions for options to be included in this code. Ted also played a major role in assembling and testing the Epic data bases; he will be recognized for this role as an author of the documentation for these data bases. 

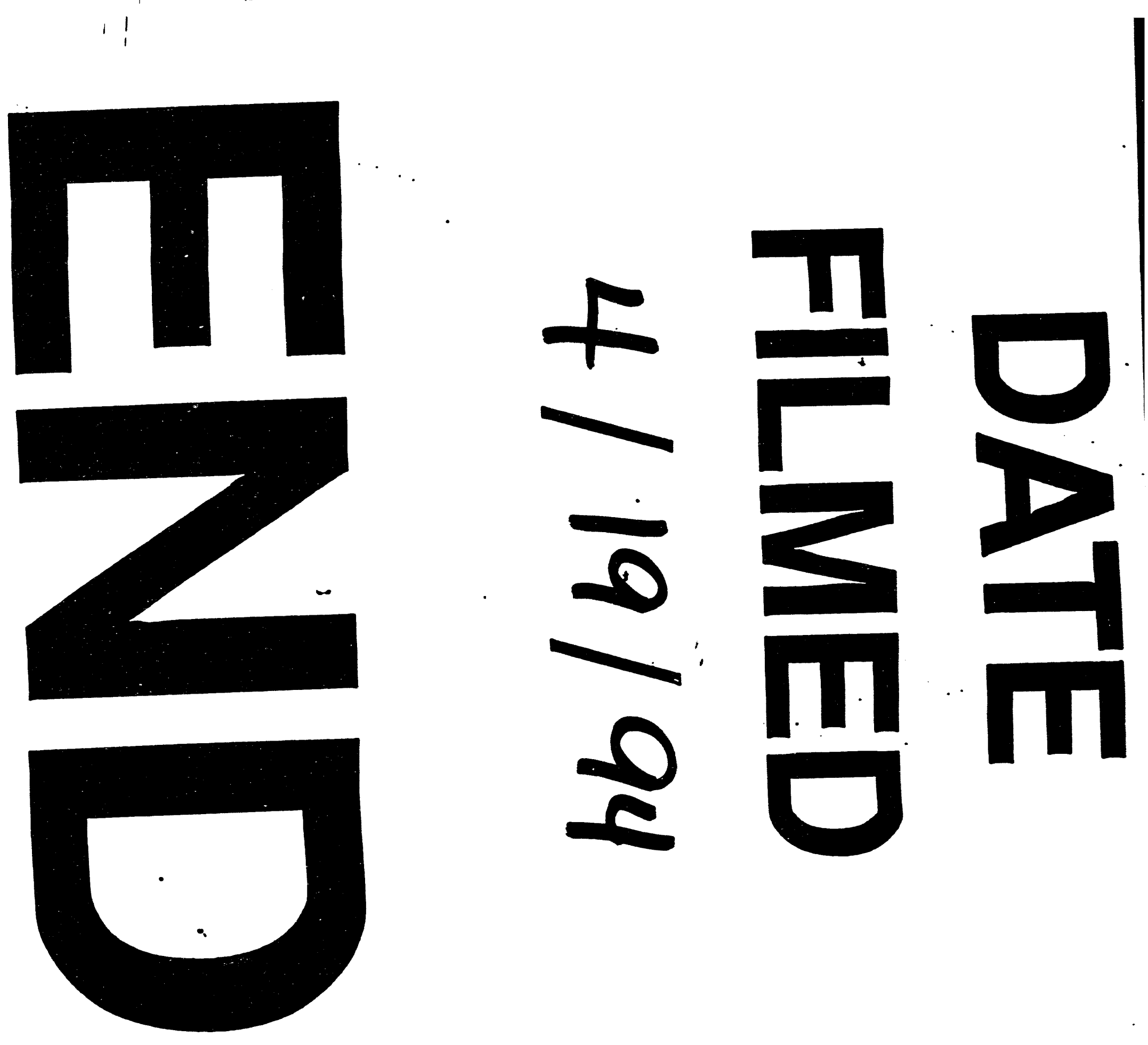
